CAHIER DE RECHERCHE \#1405E

WORKING PAPER\#1405E

Département de science économique

Department of Economics

Faculté des sciences sociales

Université d'Ottawa

Faculty of Social Sciences

University of Ottawa

\title{
Climate Policy and Induced R\&D: How Great is the Effect?
}

\author{
Nikita Lyssenko ${ }^{*}$ and Leslie Shiell ${ }^{\dagger}$
}

July 2014

\begin{abstract}
* Department of Economics, Memorial University of Newfoundland, St. John's, Newfoundland, A1C 5S7. Phone: 709-737-2149. E-mail: nlysenko@mun.ca.

${ }^{\dagger}$ Corresponding author. Department of Economics, University of Ottawa, 120, University Private, Ottawa ON K1N 6N5 Canada. E--mail: leslie.shiell@uottawa.ca.
\end{abstract}


Carbon taxes or tradable permit systems to address climate change may induce research and development in energy-related technologies. We construct a single-knowledge-stock model of $\mathrm{R} \& \mathrm{D}$, growth and climate to assess the importance of this effect. The contribution of induced R\&D is shown to be very sensitive to (i) the duplication externality, (ii) the feasibility of dedicated research subsidies to internalize inter-firm knowledge spillovers, (iii) the opportunity cost of R\&D, (iv) the initial level of research expenditure, and (v) the elasticity of substitution between energy and other factors of production. In contrast, the direction and scale of the intertemporal research spillover is of secondary importance. We find strong support for Rezai's (2011) argument that, when the business-as-usual scenario (no policy) is modeled appropriately (all externalities treated as external), sacrifices for early generations associated with optimal climate policy are minor or non-existent. Employing our preferred selections for the parameters, we find that adding an induced $R \& D$ component to the model increases the welfare impact of the first-best policy (optimally chosen carbon tax and research subsidies) by an average value of more than 400 percent, and of the second-best policy (carbon tax alone) by approximately 22 percent.

Keywords: induced technological change, climate policy modeling JEL classification: Q4, Q5

\section{Résumé}

Les taxes sur le carbone ou des systèmes de permis négociables pour lutter contre les changements climatiques peuvent induire la recherche et développement dans les technologies innovatrices au plan énergétique. Nous construisons un modèle de la $\mathrm{R} \& \mathrm{D}$, de la croissance et du climat, à un seul stock de connaissances, pour évaluer l'importance de cet effet. La contribution de la $\mathrm{R}$ \& D induite s'avère très sensible à (i) l'externalité de duplication, (ii) la possibilité de subventions de recherche dédiés à internaliser les externalités de connaissances entre entreprises, (iii) le coût d'opportunité de la R \& D par rapport à l'effet du « crowding out », (iv) le niveau initial de la $\mathrm{R} \& \mathrm{D}$, et (v) l'élasticité de substitution entre l'énergie et d'autres facteurs de production. En revanche, la direction et l'ampleur de l'externalité de recherche intertemporelle est d'une importance secondaire. Nous trouvons un appui solide pour l'argument de Rezai (2001) que les sacrifices pour les premières générations liées à la politique climatique optimale sont mineurs ou inexistants lorsque le scénario «business-as-usual » (pas de politique) est modélisé de manière appropriée (toutes les externalités internalisées). En utilisons nos sélections préférées pour les paramètres, nous constatons que l'ajout d'une module d’innovation induite à notre modèle augmente l'impact de la politique de premier rang (la taxe de carbone choisie de manière optimale et les subventions de recherche) au plan du bien-être sociale d'une valeur moyenne de plus de 400 pour cent, et de la politique de deuxième rang (taxe sur le carbone seulement) d'environ 22 pour cent.

Mots clés : l'innovation technique induite, la modélisation de la politique climatique Classification JEL : Q4, Q5 


\section{Introduction}

Carbon taxes or tradable permit systems to address climate change may induce research and development in energy-related technologies, which in turn will reduce the cost of emissions abatement. Earlier climate policy models assumed technological change was exogenous (e.g. Nordhaus and Boyer 2000) but now more models take account of endogenous technical change in one way or another. Edenhofer et al. (2006) provides a useful overview of models with endogenous technological components, including R\&D.

Despite greater awareness of induced innovation in climate policy, economists are still far from agreement on the appropriate modeling of knowledge creation through R\&D as well as the significance of its contribution to climate policy. Major strands of the literature have focused on the mechanics of modeling knowledge production through $R \& D$, the effect of induced $R \& D$ on the timing of abatement, the significance of the contribution of induced R\&D to climate policy, as well as the optimal mix of policy instruments.

Discussions on the mechanics of knowledge production have tended to focus on the modeling of inter-firm and inter-temporal knowledge spillovers and to a lesser extent on the phenomenon of a duplication externality (Goulder and Schneider 1999, Popp 2004, Gerlagh 2008, and Hart 2008). An inter-firm knowledge spillover occurs when private firms are only able to appropriate a small portion of the total benefits of their research. As a result, firms spend too little on R\&D, compared with the social optimum (Jones and Williams 2000). An inter-temporal knowledge spillover occurs when production of new knowledge today affects the productivity of research effort in the future. Depending on the nature of the inter-temporal spillover (positive or negative) and whether it is taken into account, firms will either spend too little or too much on $\mathrm{R} \& \mathrm{D}$ as a result (Jones 1995).

A duplication externality refers to the phenomenon whereby individual firms inadvertently duplicate a portion of each other's research findings, such that a doubling of aggregate $R \& D$ expenditure yields less than a doubling of new knowledge. This consideration is external to the individual firm's calculation, however, since the firm expects a payoff from knowledge that it creates regardless of the activities of other firms. Therefore, the duplication externality causes firms to spend too much on R\&D ceteris paribus (Jones 1995, Jones and Williams 2000). 
The effect of induced R\&D on the timing of abatement (Wigley et all 1996, Goulder and Mathai 2000, Hart 2008, Gerlagh et al. 2009) revolves around the lags involved in knowledge accumulation and the role of new knowledge in reducing the abatement cost of harmful emissions. Adding induced R\&D into our policy calculus raises the option of delaying more of our abatement effort to the future, when abatement will be less expensive due to the accumulation of new knowledge.

Discussions in the literature on the significance of the contribution of induced R\&D in climate policy have revolved around the role of knowledge spillovers as well as two other issues: (i) the opportunity cost of R\&D - the so-called crowding out effect - and (ii) the importance of the elasticity of substitution between energy and other factors of production. Crowding out occurs when a portion of the induced research represents a displacement of effort from other R\&D sectors which are also undersupplied. Goolsbee (1998) provides an interesting empirical perspective on the extent of this phenomenon. Assuming this effect is not taken into account, firms will overspend on R\&D ceteris paribus, and therefore the socially optimal increase in energy-efficiency R\&D may not be much different from what firms are inclined to spend anyway.

Concerns about knowledge spillovers and crowding out were first raised in the climate economics literature by Goulder and Schneider (1999). Subsequently, Popp (2004) sought to empirically calibrate the impact of these effects, in obtaining an estimate of the benefit of induced $R \& D$ associated with climate change policy. Popp estimates that adding an R\&D component increases the welfare impact of the optimal climate policy by only 9.4 percent in the central scenario - a rather modest change which he attributes to the inefficiencies associated with spillovers and crowding out. This lesson has been taken to heart by most climate policy modelers. For example, Buonanno et al. (2003) overlook the restraining effects of spillovers and crowding out, while Bosetti et al. (2006), presenting a later version of the same model, follow Popp's lead.

In contrast, Gerlagh (2008) presents a more optimistic view of crowding out and knowledge spillovers. In a three sector growth model, he finds a research dividend as a result of climate policy - i.e. aggregate research spending increases - and most of the reallocation in R\&D spending is from fossil-energy production to energy-use efficiency, while non-energy R\&D is “almost unaffected". Gerlagh's model reveals an important role for induced R\&D to 
reduce the cost of achieving a given climate target (atmospheric carbon concentration not to exceed $450 \mathrm{ppmv}$ ). Adding induced R\&D to the model (i) reduces the cost of achieving the target by approximately half in the case of full crowding out, and (ii) the cost of achieving the target becomes negligible in the case of full flexibility (partial crowding out).

The role of the elasticity of substitution between energy and other factors of production in determining the significance of induced R\&D has been emphasized by Sue Wing (2006), Shittu and Baker (2010), Acemoglu et al. (2012), and Gans (2012), among others. For a low elasticity of substitution between energy and other factors, induced R\&D in energy efficiency is significant in response to a carbon tax (or permit price). In contrast, for a high elasticity, R\&D in energy efficiency is relatively unimportant, and may even be reduced, as it is cheaper to switch to other inputs. Similarly, within the energy envelope, when fossil energy and alternative (clean) energy are highly (not very) substitutable, a carbon tax induces a significant increase (modest increase or decrease) in alternative-energy research.

Many authors have considered the optimal mix of policy instruments to deal with simultaneous distortions in terms of the environment (pollution externality) and research markets (knowledge spillovers). It is well understood that first-best policy requires an instrument for each distortion, e.g. a carbon tax for the climate externality and R\&D subsidies to internalize knowledge spillovers (Goulder and Schneider 1999, Jaffee, Newell and Stavins 2005, Fischer and Newell 2008, Massetti and Nicita 2010, Acemoglu et al. 2012). However, some have argued that differentiated subsidies for energy-efficiency research are not administratively feasible, due to either lack of technical knowledge or excessive complexity (Hart 2008, Gerlagh et al. 2009). In this case, optimal climate policy is a matter of the second best, employing only a carbon tax or tradable permits system. These authors highlight significant differences between first and second-best policies in terms of the contribution of induced R\&D.

There are also several important issues which have received relatively little attention in the literature on induced $R \& D$ to date, including (i) insufficient empirical information, (ii) problems with appropriate modeling of business-as-usual (no policy) in computational models, and (iii) the relatively common practice of abstracting from climate damages in computational modeling. The need for better empirical information about energy-efficiency R\&D is well known but difficult to solve due to lack of disaggregated data (although see on the contrary Popp (2002) and Popp and Newell (2012)). One empirical issue in particular that has received insufficient 
attention in our view is the measurement of aggregate $R \& D$ spending on energy efficiency in the base year of computational models. To our knowledge, the only modeling project to treat this issue in any kind of depth is ENTICE (Popp 2003, 2004, 2006). Others have taken either a conjectural approach to the specification of this value (e.g. Gerlagh 2008) or have treated it as a parameter to be derived from calibration (e.g. Hart 2008). We follow ENTICE in the baseline version of our model and show how our results vary under the alternative approach employed by Gerlagh (2008). We will show that the contribution of induced R\&D to climate policy is very sensitive to the choice of this value. This result is consistent with the market size effect identified in the literature on directed technical change, i.e. larger input markets will receive a greater share of R\&D investment ceteris paribus (Acemoglu 2002, Acemoglu et al. 2012).

Concern about the modeling of the business-as-usual scenario (BAU) in computational models has been raised by Shiell and Lyssenko (2008), Rezai (2011), and Rezai et al. (2012). The central issue is to determine which effects remain external to agents' consideration in the absence of corrective policy instruments and which effects are internalized. A compelling case can be made that all of the distortions listed above are treated as external by agents under business-as-usual, i.e. inter-firm and inter-temporal research spillovers, duplication externality, and the environmental externality. However, many computational models treat some distortions as external and others as internal under BAU. For example, Hart (2008) models BAU by setting emission taxes to zero, while leaving all four of the distortions above internalized. Rezai (2011) refers to this approach as a constrained optimal baseline rather than a true BAU scenario. Gerlagh (2008) treats the inter-firm knowledge spillover and the pollution externality as external under BAU (indeed he abstracts from pollution damages) but the inter-temporal knowledge spillover and the duplication externality are internal. Popp (2004) uses a more complex approximation of BAU which has been discussed in detail in Shiell and Lyssenko (2008).

The lack of consistency in treating distortions under BAU makes the results of the models difficult to interpret. However, some biases can be anticipated. For example, the treatment of the duplication effect as internal under BAU means that private agents will not over-invest in R\&D ceteris paribus, contrary to the situation where duplication is external. But the duplication externality is a compelling feature of research markets, as argued by Jones and Williams (2000). Moreover, over-investment in energy-efficiency R\&D caused by duplication in BAU compensates in some measure for knowledge spillovers and the pollution externality. Therefore, 
the additional investment in such R\&D which is stimulated by policy (e.g. a carbon tax) will be reduced compared with a scenario in which such over-investment does not occur under BAU.

This mechanism may go some way to explaining the optimistic results of Gerlagh (2008). Since he treats duplication as internal under BAU, the implementation of a carbon tax stimulates a greater amount of energy-efficiency R\&D than it would if duplication were treated as external (and therefore over-supplied) under BAU. It follows that the addition of induced innovation to his model contributes more to the reduction of abatement cost ceteris paribus than it would under the more compelling assumption of external duplication.

Comparison of results is further complicated by the practice adopted by some modelers of abstracting from climate damages. In some cases, the modeler seeks a cost-effective policy to meet a given climate target (e.g. Goulder and Schneider 1999, Gerlagh 2008), while in others the modeler seeks to characterize firms' profit maximizing choices in a partial equilibrium setting with exogenous climate policy (e.g. Sue Wing 2006, Gans 2012). The absence of a damage function in these cases reflects an implicit assumption of strong separability between climate damages and consumption, for it is only under this assumption that the results can be given a meaningful interpretation. For example, in the cost-effectiveness paradigm under the assumption of strong separability, we can estimate the gross cost of achieving a given climate target (emissions or concentration) by focusing on the production side of the model without reference to damages. ${ }^{1}$ Similarly, in a partial equilibrium setting, we can estimate firms' responses to policy independent of climate damages under the assumption of strong separability.

Nonetheless, it is abundantly clear that climate change affects both production and consumption values directly. As a result, abstracting from climate damages in computational models can lead to misleading results. ${ }^{2}$ For example, Goulder and Schneider (1999) conclude that aggregate $R \& D$ expenditure falls in response to a carbon tax, due to a large scale effect (i.e. the tax depresses GDP and incomes throughout the economy). In reality, in the absence of the tax, there is an opposite scale effect by which uncontrolled climate damages depress future GDP and incomes, and therefore the baseline path of R\&D will surely be lower than the path estimated by Goulder and Schneider. It is an empirical question to determine which scale effect dominates. It seems plausible that low levels of carbon tax could lead to an aggregate increase in

\footnotetext{
${ }^{1}$ Strong separability between climate damage and consumption goes beyond the structure of agents' utility functions; it also entails zero effects of climate on production, since consumption obviously depends on production. ${ }^{2}$ Nordhaus (2008) also identifies this problem.
} 
R\&D spending, since the environmental distortion is a first order effect while the cost of the tax is a second-order effect around zero. Similar observations can be made in the context of other models that abstract from climate damages.

We seek to explain and reconcile some of these differences of results in the literature. We proceed by constructing a single-knowledge-stock model of $\mathrm{R} \& \mathrm{D}$, growth and climate, paying particular attention to (i) the elasticity of substitution between energy and other factors of production, (ii) the opportunity cost of R\&D expenditure in relation to crowding out, (ii) the initial level of R\&D expenditure, (iii) the extent of the duplication externality, (iv) the direction (positive or negative) of the inter-temporal research externality, and (v) the difference between first-best and second-best policy. We are careful to model BAU in a theoretically consistent way, with all distortions external, and we take account of climate damages on the production side of the economy.

Our model shows that the contribution of induced R\&D to climate policy is very sensitive to the opportunity cost of $R \& D$, the initial level of $R \& D$ expenditure, the extent of the duplication externality, and the difference between first-best and second-best policy (i.e. internalization of inter-firm knowledge spillovers). The results are also quite sensitive to the value of the elasticity of substitution. In contrast, the results are not very sensitive to the direction of the inter-temporal knowledge spillover. Employing our preferred selections for the relevant parameters, we find that adding an induced R\&D component to our single-knowledge-stock model increases the welfare impact of the first-best climate policy (optimally chosen carbon tax and research subsidies) by an average value of more than 400 percent, and of the second-best climate policy (carbon tax alone) by approximately 22 percent. For comparison, we note that Popp (2004) reports an increase in the welfare impact of climate policy of only 9 percent in the base case of the ENTICE model. Clearly, the scale of the contribution of induced R\&D depends in an important way upon the feasibility of differentiated research subsidies. Yet even without such subsidies, it would appear that induced $R \& D$ makes a significant contribution to climate policy.

The remainder of the paper is structured as follows. Section II presents our singleknowledge-stock model of R\&D, growth and climate. Section III presents the initial values of stocks and parameters, as well as the calibration of the model. Section IV presents our results and Section V concludes. 


\section{Single-knowledge-stock model of $R \& D$, growth and climate}

\section{Model structure}

We present a single-region growth model with an environmental module to account for negative impacts of greenhouse gas emissions. The model borrows heavily from ENTICE (Popp 2004) which in turn is based on the structure of Nordhaus' DICE model (Nordhaus 1994, 2008, Nordhaus and Boyer 2000).

Time proceeds in discrete steps of 10 years each, with periods denoted $t=1, \ldots, T$. The initial period corresponds with the decade 2000-2010. The terminal period is $32(\mathrm{~T}=32)$, for a total planning horizon of 320 years.

In any given period, gross output, $Q_{t}$, is given by the CES (constant elasticity of substitution) production function

$Q_{t}=A_{t}\left[\alpha_{K} K_{t}^{\gamma}+\alpha_{L} L_{t}^{\gamma}+\left(1-\alpha_{K}-\alpha_{L}\right) E N_{t}^{\gamma}\right]^{\frac{1}{\gamma}}, \quad \gamma<1$

where $K_{t}$ denotes physical capital, $L_{t}$ denotes labour, $E N_{t}$ denotes energy services, and $A_{t}$ denotes total factor productivity. For unitary elasticity (alternatively $\gamma=0$ ), (1) reduces to the CobbDouglas functional form

$Q_{t}=A_{t} K_{t}^{\alpha} L_{t}^{\beta} E N_{t}^{1-\alpha-\beta}$.

Labour and total factor productivity are assumed to follow exogenous trends, growing exponentially but at declining rates. Details of these trends are discussed in Nordhaus (2008).

Physical capital evolves according to the difference equation ${ }^{3}$

$$
K_{t+1}=\left(1-\delta_{K}\right)^{\Delta} K_{t}+\Delta \cdot I_{t} \quad\left(P_{t}^{K}\right)
$$

where $I_{t}$ represents investment, $\delta_{K}$ represents the annual depreciation rate, and $\Delta$ represents the period duration (10 years). New capital is costly to install, which is reflected in a one-parameter adjustment cost factor, $\frac{\eta}{2} \frac{I_{t}^{2}}{K_{t}}$. This factor is increasing and quadratic in $I_{t}$, reflecting increasing marginal cost of adjustment within each period, but decreasing in $K_{t}$, reflecting decreasing cost in the level of existing capital. This specification follows McKibbin and Wilcoxen (1999), and it is similar to a two parameter specification, $\frac{\eta}{2}\left(I_{t} / K_{t}-\zeta\right)^{2} K_{t}$, employed by Goulder and Summers (1989).

\footnotetext{
${ }^{3}$ The variable in parentheses after the equation represents the shadow value which will be employed subsequently.
} 
Energy services are provided by an effective fuel input, $\widehat{F}_{t}$, which is carbon based, and by energy-related human capital, $H_{t}$, according to the CES function

$E N_{t}=\left[\alpha_{H} H_{t}^{\rho}+\alpha_{F} \hat{F}_{t}^{\rho}\right]^{1 / \rho}, \quad \rho<1 \quad\left(P_{t}^{E}\right)$

The effective fuel input is derived from gross fuel, $F_{t}$, according to the relationship

$\widehat{F_{t}}=\frac{F_{t}}{\Phi_{t}}$

where $1 / \Phi_{t}$ represents exogenously increasing technical change.

Energy-related human capital evolves according to the difference equation

$h_{t} \equiv H_{t+1}-H_{t}=\Delta \cdot a R_{t}^{b} H_{t}^{\phi}, \quad\left(P_{t}^{H}\right)$

where $R_{t}$ represents energy-related research spending. Note that, unlike physical capital, human capital does not depreciate in this formulation, which is consistent with Popp (2004).

Net output, $Y_{t}$, is given by the function

$Y_{t}=D_{t} Q_{t}-P_{t} F_{t} \quad\left(P_{t}^{Y}\right)$

where $D_{t}$ denotes the climate-related damage function, $F_{t}$ denotes the carbon-based fuel (also equal to emissions), and $P_{t}$ denotes the extraction cost of fuel. The damage function is specified as

$D_{t}=\frac{1}{1+\xi T E_{t}^{2}}$

where $T E_{t}$ denotes deviation in global mean temperature since 1900 (atmosphere and upper ocean level).

The definition of net output (6) reflects the flow of real resources and is relevant to the solution of the social planner's problem, which we will discuss below. In contrast, individual agents may also face a carbon tax and a research subsidy, which we denote $\tau_{t}$ and $z_{t}$ respectively, and receive transfers from the government, which we denote $G T_{t}$. From this perspective, net output is represented as

$Y_{t}=D_{t} Q_{t}-\left(P_{t}+\tau_{t}\right) F_{t}+z_{t} R_{t}+G T_{t} \quad\left(P_{t}^{Y}\right)$

The inclusion of transfers allows us to model the disposition of carbon tax revenues net of research subsidy payments. In the case where revenues are returned in a lump-sum manner to agents, the terms $\left(z_{t} R_{t}-\tau_{t} F_{t}\right)$ and $G T_{t}$ cancel out in the aggregate, returning us to condition (6). However, these terms do not necessarily cancel out at the level of individual agents; rather, 
agents consider $G T_{t}$ exogenous and adjust their choice of $F_{t}$ in response to $\tau_{t}$ and their choice of $R_{t}$ in response to $z_{t}$.

The cost of the carbon fuel $P_{t}$ would be equivalent to the market price if (i) there was an inexhaustible supply of the resource at a constant cost of extraction, and (ii) the market was perfectly competitive. However, the geology of carbon resources is one of scarcity, in which there is a finite supply of each grade of the resource. Therefore, consumption entails scarcity rents, as society moves on to progressively more costly sources of supply. It is an open question whether energy markets actually incorporate scarcity rents into the price of fuel. However, accounting for deviations from full-cost pricing would take us too far afield from our present topic, and therefore for simplicity we assume that the market price of fuel fully includes the associated scarcity rent. Following Nordhaus and Boyer (2000) and Popp (2004), we model the cost, $P_{t}$, as an increasing function of the cumulative amount of fuel consumed to date, $C m_{t}$. In particular,

$P_{t}=\omega_{1}+\omega_{2}\left(\frac{C m_{t}}{\Omega}\right)^{4}$

and

$C m_{t+1}=C m_{t}+\Delta \cdot F_{t} . \quad\left(P_{t}^{C m}\right)$

(Recall that $\Delta$ is the period duration - 10 years). We derive the market price of fuel, including scarcity rent, in a subsequent section.

The global climate system follows Nordhaus' DICE model and is summarized by the following six equations:

$$
\begin{array}{ll}
M A T_{t+1}=b_{11} M A T_{t}+\Delta \cdot F_{t}+b_{21} M U_{t} & \left(P_{t}^{M}\right) \\
F O R C E_{t}=3.8\left(\frac{\ln \left(M A T A V_{t} / 596.4\right)}{\ln 2}\right) & \left(P_{t}^{M U}\right) \\
M U_{t+1}=b_{12} M A T_{t}+b_{22} M U_{t}+b_{32} M L_{t} & \left(P_{t}^{M L}\right) \\
M L_{t+1}=b_{33} M L_{t}+b_{23} M U_{t} & \left(P_{t}^{T E}\right) \\
T E_{t+1}=T E_{t}+C_{1}\left(F O R C E_{t+1}-\frac{3.8}{C_{2}} T E_{t}-C_{3}\left(T E_{t}-T L_{t}\right)\right) & \left(P_{t}^{T L}\right)
\end{array}
$$

The variables are: carbon mass in the atmosphere, $M A T_{t}$; carbon mass in the "upper reservoir" (biosphere and upper oceans), $M U_{t}$; carbon mass in the lower oceans, $M L_{t}$; radiative forcing, 
$F O R C E_{t}$; and temperature in the lower ocean level, $T L_{t}$. The variable $M A T A V_{t}$ represents the two-period moving average of $M A T_{t}$. A detailed discussion is provided in Nordhaus (2008) and Nordhaus and Boyer (2000). In a nutshell, emissions accumulate in the atmosphere (MAT), leading with a lag to higher temperatures $(T E)$.

Preferences are expressed in terms of a representative agent who derives instantaneous utility, $U$, from per capita consumption, according to the logarithmic function $U\left(C_{t} / L_{t}\right)=\ln \left(C_{t} / L_{t}\right)$.

This function exhibits the familiar Inada condition,

$\lim _{C \rightarrow 0^{+}} U=\infty$.

Global welfare is measured by a utilitarian function

$W=\sum_{t=1}^{T} \frac{L_{t} U\left(C_{t} / L_{t}\right)}{(1+\theta)^{\Delta(t-1)}}$

where $\theta$ represents the pure rate of time preference.

The model is closed by the budget constraint

$Y_{t}=C_{t}+I_{t}+R_{t}+\left(\frac{\eta}{2}\right) \frac{I_{t}^{2}}{K_{t}}$,

i.e. net output is allocated among consumption, physical capital investment, energy R\&D expenditure, and capital adjustment costs. We make adjustments to the budget constraint in the next section, to account for crowding out of research spending in non-energy related (unmodeled) research sectors in the manner of Popp (2004). Thus we refer to (19) as the unadjusted budget constraint.

\section{Research externalities and crowding out}

The parameter $b$ in the research function (5) characterizes the duplication externality in research (Jones 1995). Since research effort is spread out across many firms, it is likely that some portion of new knowledge creation will be duplicated. Therefore, we expect $0<b<1$.

The parameter $\phi$ characterizes the intertemporal knowledge spillover. When $\phi>0$, researchers "stand on the shoulders of giants," as new discoveries become easier with more knowledge. When $\phi<0$, research is a process of "fishing out the pond," as new discoveries become more difficult as knowledge is accumulated. When $\phi=0$, the productivity of research is not affected by the amount of existing knowledge. Formally, this characteristic relates to the 
second derivative of the research function, $\frac{\partial^{2} h_{t}}{\partial R_{t} \partial H_{t}}$, which is positive, negative, or zero as $\phi$ is positive, negative or zero (Jones 1995).

The value of $\phi$ also determines returns to the amount of existing knowledge in research. This characteristic relates to the second derivative $\frac{\partial^{2} h_{t}}{\partial H_{t}^{2}}$. Assuming $\phi>0$, so that the first derivative $\frac{\partial h_{t}}{\partial H_{t}}$ is positive (standing on the shoulders), the second derivative is positive if $\phi>1$, zero if $\phi=1$, and negative if $0<\phi<1$. These cases refer respectively to increasing, constant and decreasing returns to $H_{t}$ in the research process.

We employ a leakage parameter, $\ell \in[0,1]$, to account for inter-firm knowledge spillovers. In particular, we assume that a firm engaged in R\&D can only appropriate $(1-\ell)$ of the resulting benefits. ${ }^{4}$

We assume that the duplication externality and intertemporal knowledge spillover are external to an individual firm's decision making, since an atomistic firm conducting R\&D (i) expects to get paid for the results of its research whether another firm arrives at the same results or not, and (ii) the firm will not be able to appropriate the benefit that its discoveries confer on researchers in the future. These assumptions mean that individual firms expect constant returns to research effort, $R$, rather than the diminishing returns inherent in the research function (5) (i.e. $\left.\partial^{2} h_{t} / \partial R_{t}^{2}<0\right)$. We follow Jones and Williams (2000) in basing the firm's perceived return to $\mathrm{R} \& \mathrm{D}$ on the average product of research effort, $v_{t} \equiv \Delta a R_{t}^{b-1} H_{t}^{\phi}$. In particular, the firm's perceived return is given by an adjusted research function $h_{t}=(1-\ell) v_{t} R_{t} . \quad\left(P_{t}^{H}\right)$

The fact that firms' perceived returns to $R \& D\left(5^{\prime}\right)$ differ from the social return (5) may result in unaccounted opportunity costs (or opportunity benefits) related to crowding out of R\&D spending from other (unmodeled) research sectors. In all research sectors, firms invest in R\&D to the point where the perceived returns are equilibrated with the returns to investment in physical capital. Remembering that $P^{H}$ and $P^{K}$ are the shadow values of knowledge and physical capital respectively, we have the investment equilibrium condition for any research sector

\footnotetext{
${ }^{4}$ Gerlagh (2008) defines an appropriation parameter which is equivalent to $(1-\ell)$.
} 
$P^{H}(1-\ell) v=P^{K}$,

or alternatively

$\frac{P^{H}}{P^{K}}(1-\ell) v=1$

We make a further distinction between the shadow value of knowledge capital when spillover and external effects have been internalized by individual agents and when such effects have not been internalized. The determining factor in these cases is policy: in the presence of appropriate policy instruments, some portion of spillover and external effects will be internalized, while in the absence of policy instruments, none of these effects will be internalized. Henceforth, we use $P^{H}$ to denote the shadow value of knowledge capital in the absence of policy instruments (the perceived shadow value), and $\hat{P}^{H}$ to denote the shadow value in unmodeled research sectors (non-energy) under full internalization of spillovers and external effects (the true shadow value).

Under full internalization of spillover and external effects, agents invest in a knowledge stock to the point where the social marginal benefit and cost are equalized. In this case, crowding out of research spending in unmodeled research sectors is not a concern, since the agent's marginal cost of new research spending reflects the social opportunity cost. In contrast, crowding out of research spending in unmodeled sectors becomes a concern when spillovers and external effects in those sectors have not been internalized, since in that case the agent's marginal cost of new research spending does not reflect the social opportunity cost. We proceed on the assumption that spillovers and external effects have not been internalized in unmodeled research sectors; therefore we use $P^{H}$ as the shadow value of knowledge capital in the research equilibrium condition (20). The true shadow value $\hat{P}^{H}$ will come into play below.

The left-hand side of (20) represents the firm's payoff to R\&D in terms of the investment numeraire, $I$, and the right-hand side represents the firm's opportunity cost. But $v$ represents the average product of $R$; to determine the social opportunity cost associated with crowding out we need the marginal product of $R$ in unmodeled sectors. Defining $\psi_{h}$ as the (social) marginal product of $R$, in units of new knowledge, $h$, we have from (5) $\psi_{h}=\Delta a b R^{b-1} H^{\phi}=b v$. Substituting for $v$ in the investment condition (20) yields $\frac{P^{H}}{P^{K}}(1-\ell) \frac{\psi_{h}}{b}=1$. 
Now define $\psi$ as the social marginal product of $R$ in terms of the investment numeraire; i.e. $\psi=\frac{\hat{P}^{H}}{P^{K}} \psi_{h}$

where we have used $\hat{P}^{H}$ to reflect the social valuation of the knowledge stock. Substituting into (21) and rearranging yields

$\psi=\frac{\hat{P}^{H}}{P^{H}} \frac{b}{1-\ell}$.

This expression provides the basis for ad hoc adjustments to the budget constraint, to account for crowding out in unmodeled (non-energy efficiency) research sectors. The unadjusted budget constraint was given above in (19); this is the budget constraint perceived by individual firms. In the case where $R$ comes entirely at the expense of $I$, this constraint indicates an opportunity cost in terms of physical capital investment of unity. In contrast, when energy related R\&D spending comes at the expense of other (unmodeled) R\&D sectors, (22) indicates that the opportunity cost may differ from unity, depending on the values of $b, \ell, P^{H}$, and $\hat{P}^{H}$.

Table 1 provides partial insight into the value of $\psi$ by considering different combinations of $b$ and $\ell$ under the assumption that $\hat{P}^{H}=P^{H}$. We observe that $\psi$ increases in the extent of leakage (i.e. larger values of $\ell$ ) but decreases in the extent of the duplication externality (i.e. smaller values of $b$ ). These results are intuitive. With greater leakage, firms will further reduce their R\&D investment below the social optimum, leading to a higher social marginal product $\psi$. In contrast, since firms ignore the duplication externality, an increase in duplication (smaller value of $b$ ) will further reduce the socially optimal level of spending compared with firms' actual investments (firms over invest). With over investment by firms, the marginal product of R\&D is lower than the optimal level. The table highlights combinations of $b$ and $\ell$ for which these two countervailing effects exactly offset; i.e. for which $\psi=1$ (assuming $\hat{P}^{H}=P^{H}$ ). For interest, we note that Popp (2004) assumes values of $\ell=0.75$ and $b=0.2$, which corresponds with $\psi=0.8$ in Table 1. In this case, the duplication externality dominates the effect of leakage; i.e. firms' over investment from ignoring duplication exceeds their underinvestment from knowledge spillovers. The net effect is an opportunity benefit of crowding out $\mathrm{R} \& \mathrm{D}$ from unmodeled sectors, as this reduces overinvestment in these sectors. ${ }^{5}$

In fact, energy related R\&D may crowd out both physical capital investment and spending in other R\&D sectors. To account for this, we follow Popp (2004) and define

\footnotetext{
${ }^{5}$ In contrast, Popp (2004) uses a value of $\psi=4$, as he assumes firms internalize the duplication externality.
} 
crowdout $\in[0,1]$ as the proportion of energy-related $R \& D$ spending which is obtained by crowding out R\&D spending in other (unmodeled) sectors. We then use crowdout and $\psi$ to adjust physical capital investment, $I_{t}$, in the budget constraint to approximate the effects of crowding out. First, we note that $(1-$ crowdout $) R_{t}$ represents energy R\&D spending which competes with $C_{t}$ and $I_{t}$ for the allocation of $Y_{t}$ in the budget constraint. In contrast, crowdout . $R_{t}$ represents energy R\&D spending which does not compete with $C_{t}$ and $I_{t}$ for the allocation of $Y_{t}$, as it is financed by taking resources away from non-energy R\&D sectors (unmodeled) which have already been allocated resources. ${ }^{6}$ However, crowdout $\cdot R_{t}$ does entail opportunity costs, which, in the absence of explicit modeling, can be represented by an equivalent charge on $Y$, given by crowdout $\cdot R_{t} \cdot \psi$. Therefore, our adjusted budget constraint is $Y_{t}=C_{t}+I_{t}+(1-$ crowdout $) R_{t}+$ crowdout $\cdot R_{t} \cdot \psi+\left(\frac{\eta}{2}\right) \frac{I_{t}^{2}}{K_{t}}$.

Collecting terms, the adjusted budget becomes ${ }^{7}$

$Y_{t}=C_{t}+I_{t}+R_{t}[1+(\psi-1) \cdot$ crowdout $]+\left(\frac{\eta}{2}\right) \frac{I_{t}^{2}}{K_{t}}$.

Note that the adjustment term is negative when $\psi<1$. In this case, the opportunity cost of an additional dollar of $R$ is less than one dollar (opportunity benefit), as unmodeled R\&D sectors have been over allocated resources in the initial equilibrium, compared with the social optimum.

\section{Policy scenarios}

The solution of the model involves maximization of (18) subject to an appropriate combination of constraints (details below). The maximization can be given positive or normative interpretations, depending on the policy scenario. We consider three policy scenarios: businessas-usual (BAU), first-best optimal policy, and second-best optimal policy.

In BAU, no policy is implemented to control greenhouse gas emissions. In this scenario, a representative agent chooses values of the flow variables $C, E N, F, R, Y, I$ to maximize (18) subject to a subset of the constraints of the model (details below). This exercise is given a positive interpretation, according to which maximization by a representative agent is viewed as a mathematical expedient for replicating general equilibrium in a decentralized market economy.

\footnotetext{
${ }^{6}$ This discussion indicates that $Y_{t}$ should be viewed as output net of R\&D inputs to non-energy sectors.

${ }^{7}$ Popp (2004) employs $\psi$ rather than $(\psi-1)$ in the final adjustment expression. In effect, he assumes both that (i) the full amount of $R_{t}$ is funded from net output, $Y_{t}$, and therefore competes with $C_{t}$ and $I_{t}$, and that (ii) a portion crowdout $\cdot R_{t}$ creates an opportunity cost in non-energy research sectors. These assumptions cannot both be true.
} 
First-best optimal policy corresponds with a normative interpretation of the maximization problem. In this interpretation, the maximizing agent is an ideal social planner and the objective function (18) is considered to embody certain desirable ethical properties. Emissions control and R\&D levels are chosen to maximize the welfare function (18) jointly with other control variables.

The resulting solution of the planner's problem may be viewed as equivalent to the outcome in a decentralized economy where the regulator has sufficient instruments to induce private agents to choose the socially optimal levels of all variables. In the presence of climate and R\&D externalities, this outcome typically requires separate instruments for the control of greenhouse gas emissions (e.g. carbon tax or tradable emission permits) and R\&D investments (R\&D subsidies or taxes). We have anticipated this outcome with our modified definition of net output in $\left(6^{\prime}\right)$, which includes a carbon tax $\tau_{t}$ and a research subsidy $z_{t}$.

Despite the theoretical controllability of the first-best solution, several authors have expressed skepticism that R\&D subsidies specifically tailored for alternative energy would be feasible, either due to lack of technical knowledge or administrative complexity (e.g. Hart 2008, Gerlagh et al. 2009). In the absence of tailored R\&D instruments, the best the regulator can do is to choose the level of the emissions policy variable to maximize utility while taking account of its effects on both emissions and spending on R\&D. With only one instrument and two market distortions, this approach will not in general achieve the social optimum (first best). Therefore, we refer to this scenario as the second best.

To compare the effects of endogenous and exogenous $R \& D$, two variants of the first and second best policy scenarios are computed. With endogenous R\&D, research spending is (i) chosen to maximize welfare jointly with the other control variables (first best), or (ii) chosen indirectly through the welfare maximizing choice of the emissions control instrument (second best). Under exogenous $R \& D$, the level of research spending in each period is constrained to equal the level obtained in the BAU scenario. In other words, policy choices do not induce any additional $\mathrm{R} \& \mathrm{D}$ in this scenario.

\section{First-order conditions}

The BAU and first-best scenarios can be solved by deriving the first-order (necessary) conditions analytically and then numerically solving the resultant system of equations. This 
approach makes it easy to accommodate multiple externalities by adjusting the first-order conditions in an appropriate manner. In contrast, solving for the second best is more complicated. First, we must characterize the decentralized economy by the appropriate set of first-order conditions. Second, we must maximize the objective function (18) subject to this set of first-order conditions. In this manner, two optimizations are folded into one: first, the representative agent's maximization characterizing the decentralized economy conditional on the time path of the emissions control variable (e.g. a carbon tax); and second, the social planner's choice of the emissions control variable (and associated equilibrium) to maximize social welfare. For simplicity, we assume that both the representative agent and the social planner have the same preferences, as embodied in the objective function.

To begin, we derive the conditions for first-best policy (i.e. the social planner's problem). In this case, the task is to maximize (18) with respect to the flow variables $C, E N, F, R, Y, I$, FORCE and stock variables $K, H, C m, M A T, M U, M L, T E, T L,{ }^{8}$ subject to (i) constraints (1)(16) and $\left(19^{\prime}\right)$, (ii) initial values of the stocks, (iii) non-negativity constraints on all the variables, (iv) T given, and (v) endogenous terminal stock values.

The non-negativity constraints are not binding on $H$ and $\mathrm{Cm}$, since these stocks accumulate but never depreciate. The Inada condition (17) ensures an interior solution with respect to $C$. It follows through the budget equation $\left(19^{\prime}\right)$ that $Y$ must be strictly positive, and therefore, due to the properties of the CES functions (1) and (3), K, EN and $F$ must be strictly positive as well. ${ }^{9}$ Strictly positive values of $F$, in turn, entail strictly positive values of the environmental variables $M A T, M U, M L, T E$, and $T L$, through conditions (10) - (15). Finally, the exploding marginal product of $R$ at the corner in (5) (i.e. $\lim _{R_{t} \rightarrow 0^{+}} \partial h_{t} / \partial R_{t}=\infty$ ) ensures an interior solution with respect to $R$. It follows that a corner solution is only possible with respect to $I$. In the numerical simulations, we model an explicit complementary slackness relationship to account for this possibility. However, such a solution never comes into play, and therefore in the statement of the first-order conditions below we focus only on interior solutions.

\footnotetext{
${ }^{8}$ The time subscripts are dropped for simplicity.

${ }^{9}$ Focusing on (1), the arguments of the CES functional form are either essential (case of $\gamma<0$ ) or they are nonessential but have exploding marginal products at the corner (e.g. $\left.\lim _{K_{t} \rightarrow 0^{+}} \partial Q_{t} / \partial K_{t}=\infty\right)($ case of $0<\gamma<1)$ in which case it is never optimal to set the value to zero. For $\gamma=0$ (Cobb-Douglas case), the arguments are both essential and have exploding marginal products at the corner. Note that strictly positive $F$ means that human capital supplements but never eliminates the carbon-based fuel in the provision of energy services.
} 
We construct the Lagrangian for the planner's problem in the usual manner and obtain the following first-order conditions.

$$
\begin{aligned}
& P_{t}^{Y}=\frac{L_{t} / C_{t}}{(1+\theta)^{\Delta(t-1)}} \\
& \Delta \cdot P_{t}^{K}-P_{t}^{Y}\left(1+\eta \frac{I_{t}}{K_{t}}\right)=0 \\
& P_{t}^{E}=P_{t}^{Y} D_{t} A_{t}\left[\alpha_{K} K_{t}^{\gamma}+\alpha_{L} L_{t}^{\gamma}+\left(1-\alpha_{K}-\alpha_{L}\right) E N_{t}^{\gamma}\right]^{\frac{1-\gamma}{\gamma}}\left(1-\alpha_{K}-\alpha_{L}\right) E N_{t}^{\gamma-1} \\
& \left(P_{t}^{E}=P_{t}^{Y}(1-\alpha-\beta)\left(\frac{D_{t} Q_{t}}{E N_{t}}\right) \text { for Cobb-Douglas }\right) \\
& P_{t}^{E}\left(\frac{E N_{t}}{F_{t}}\right)^{1-\rho} \alpha_{F} \Phi^{-\rho}=-\Delta P_{t}^{M}-\Delta P_{t}^{C m}+P_{t}^{Y} P_{t} \\
& \Delta P_{t}^{H} a b R_{t}^{b-1} H_{t}^{\phi}-P_{t}^{Y}[1+(\psi-1) \cdot \text { crowdout }]=0 \\
& P_{t+1}^{K}\left(1-\delta_{K}\right)^{\Delta}=P_{t}^{K}-P_{t+1}^{Y} D_{t+1} A_{t+1}\left[\alpha_{K} K_{t+1}^{\gamma}+\alpha_{L} L_{t+1}^{\gamma}+\left(1-\alpha_{K}-\alpha_{L}\right) E N_{t+1}^{\gamma}\right]^{\frac{1-\gamma}{\gamma}} \alpha_{K} K_{t+1}^{\gamma-1} \\
& -P_{t+1}^{Y} \frac{\eta}{2}\left(\frac{I_{t+1}}{K_{t+1}}\right)^{2} \\
& \left(P_{t+1}^{K}\left(1-\delta_{K}\right)^{\Delta}=P_{t}^{K}-P_{t+1}^{Y} \alpha\left(\frac{D_{t+1} Q_{t+1}}{K_{t+1}}\right)-P_{t+1}^{Y} \frac{\eta}{2}\left(\frac{I_{t+1}}{K_{t+1}}\right)^{2} \text { for Cobb - Douglas }\right) \\
& P_{t+1}^{H}\left[1+\Delta \phi a R_{t+1}^{b} H_{t+1}^{\phi-1}\right]=P_{t}^{H}-P_{t+1}^{E}\left(\frac{E N_{t+1}}{H_{t+1}}\right)^{1-\rho} \alpha_{H} \\
& P_{t+1}^{C m}=P_{t}^{C m}+P_{t+1}^{Y} F_{t+1} \frac{4 \omega_{2}}{\Omega^{4}} C m_{t+1}^{3} \\
& P_{t+1}^{M} b_{11}=P_{t}^{M}-P_{t}^{T E}\left(\frac{3.8 \cdot C_{1}}{\ln 2} / M A T_{t+1}\right)-P_{t+1}^{M U} b_{12} \\
& P_{t+1}^{M U} b_{22}=P_{t}^{M U}-P_{t+1}^{M} b_{21}-P_{t+1}^{M L} b_{23} \\
& P_{t+1}^{M L} b_{33}=P_{t}^{M L}-P_{t+1}^{M U} b_{32} \\
& P_{t+1}^{T E}\left(1-\frac{3.8 \cdot C}{C_{2}}-C_{1} C_{3}\right)=P_{t}^{T E}-P_{t+1}^{T L} C_{4}+P_{t+1}^{Y} \frac{\left(D_{t+1} Q_{t+1}\right)\left(\alpha_{1}+2 \alpha_{2} T E_{t+1}\right)}{\left(1+\xi T E_{t+1}^{2}\right)} \\
& P_{t+1}^{T L}\left(1-C_{4}\right)=P_{t}^{T L}-P_{t+1}^{T E} C_{1} C_{3}
\end{aligned}
$$

We have the standard finite-horizon transversality conditions for non-negative stocks: ${ }^{10}$

\footnotetext{
${ }^{10}$ Many dynamic optimization models in the literature impose a steady-state transversality condition $I_{T}=\delta_{K} K_{T}$, which indicates that terminal investment in physical capital must equal depreciation (e.g. Nordhaus and Boyer 2000, Popp 2004). This approach, proposed originally by Barr and Manne (1967), is common in finite-horizon approximations of infinite-horizon problems. However, the present model does not have a steady state, due to the continually increasing fuel price (8), and therefore Barr and Manne's transversality condition is not appropriate here.
} 


$$
P_{T}^{K} K_{T}=P_{T}^{H} H_{T}=P_{T}^{C m} C m_{T}=P_{T}^{M} M A T_{T}=P_{T}^{M U} M U_{T}=P_{T}^{M L} M L_{T}=P_{T}^{T E} T E_{T}=P_{T}^{T L} T L_{T}=0
$$

Since the terminal stocks are all strictly positive (non-negativity constraints non-binding), condition (36) yields terminal shadow prices equal to zero.

The first-order conditions for BAU differ in a number of ways from those above. The problem for the representative agent is to maximize (18) with respect to the flow variables $C$, $E N, F, R, Y, I$ and stock variables $K, H, C m$, subject to (i) constraints (1) - (4), $\left(5^{\prime}\right),\left(6^{\prime}\right),(7)-$ (9), (16) and (19), (ii) initial values of the stocks, (iii) non-negativity constraints on all the variables, (iv) T given, and (v) endogenous terminal stock values. The differences from the first best are in (i) the perceived return to research $\left(\left(5^{\prime}\right)\right.$ instead of (5)),(ii) the use of the unadjusted budget constraint $\left((19)\right.$ instead of $\left.\left(19^{\prime}\right)\right)$, which entails that crowding out of non-energy research is not taken into account (external effect), and (iii) the omission of the environmental dynamics (10) - (15) (environmental variables assumed exogenous). We have also substituted the definition of net output with the carbon tax and research subsidy (6') in place of (6) to facilitate our discussions later of (i) the decentralization of the first-best solution and (ii) the second best. However, (6 $6^{\prime}$ and (6) are the same in BAU, since $\tau=z=G T=0$ in this scenario.

The first-order conditions for BAU include (23), (24), (25), (28) and (30) from above, plus

$P_{t}^{E}\left(\frac{E N_{t}}{F_{t}}\right)^{1-\rho} \alpha_{F} \Phi^{-\rho}=-\Delta P_{t}^{C m}+P_{t}^{Y}\left(P_{t}+\tau_{t}\right)$

$\Delta \cdot P_{t}^{H}(1-\ell) v_{t}+P_{t}^{Y}\left(z_{t}-1\right)=0$

$P_{t+1}^{H}=P_{t}^{H}-P_{t+1}^{E}\left(\frac{E N_{t+1}}{H_{t+1}}\right)^{1-\rho} \alpha_{H}$

We see here (i) the absence of the pollution shadow value $P_{t}^{M}$ in (37) (compared with (26), (ii) the presence of the leakage parameter in (38) reflecting the focus on private returns to $R \& D$ only, (iii) the use of the average product of research $v_{t}$ in (38) instead of the marginal product (compared with 27)), (iv) the lack of accounting of crowding out of non-energy research in (38) (compared with (27)), (v) the lack of accounting of inter-temporal research spillovers in (39) (compared with (29)), and (v) the lack of accounting of environmental impacts (absence of conditions (31) - (35)).

The difference in the first-order conditions between the first-best and BAU problems is one of perception. The two scenarios share the same physical reality, described by the structural equations (1) - (16) and $\left(19^{\prime}\right)$. However, in BAU, the agent ignores certain aspects of reality, 
yielding the differences in the first-order conditions described above. The solution to each scenario involves the simultaneous solution of the structural equations and the corresponding first-order conditions, yielding different outcomes. For example, research output is actually determined by (5) in BAU (structural equation) even though agents perceive it to be determined by $\left(5^{\prime}\right)$ (basis of the FOC). Similarly, the environmental impacts in BAU are determined by (10) $-(15)$ even though agents believe these impacts to be exogenous.

\section{The decentralized economy}

The decentralized economy with active policy measures is characterized by the same set of equations as BAU with the difference that at least one of the policy variables $\tau_{t}$ or $z_{t}$ is nonzero. In the case of decentralizing the first-best, the value of $\tau_{t}$ must be chosen to make (37) and (26) identical, and similarly the value of $z_{t}$ must be chosen to make (38) and (27) identical. For the carbon tax, we obtain the first-best value ${ }^{11}$

$\tau_{t}^{*}=\frac{-\Delta P_{t}^{M}}{P_{t}^{Y}}$.

The choice of the first-best $z_{t}^{*}$ is more complex. We have used one research subsidy to deal with two research spillovers - the inter-firm spillover and the inter-temporal spillover. As a result, we are not able to fully control the knowledge-stock shadow value, $P_{t}^{H}$. In effect, firms continue to estimate the shadow value based on (39) even though this condition omits the intertemporal spillover effect which is present in (29). Nonetheless, by choosing an appropriate value of $z_{t}$ in every period, we are able to offset the firms' suboptimal value of $P_{t}^{H}$ and induce them to choose the socially optimal value of all other variables. We use the asterisk notation to indicate optimal values of variables (derived from the planner's problem) - e.g. $P_{t}^{H^{*}}-$ and unaccented notation to indicate sub-optimal values determined by the firms' first-order conditions in the decentralized economy - e.g. $P_{t}^{H}{ }^{12}$ Since we can control all variables other than $P_{t}^{H}$, we substitute the optimal values of these variables into (38) and choose the value of $z_{t}$ which makes (38) and (27) identical. We obtain

$z_{t}^{*}=\Delta \frac{P_{t}^{H^{*}}}{P_{t}^{Y^{*}}} a b R_{t}^{b-1^{*}} H_{t}^{\phi^{*}}\left[1-\frac{P_{t}^{H}}{P_{t}^{H^{*}}} \frac{(1-\ell)}{b}\right]-(\psi-1) \cdot$ crowdout

\footnotetext{
${ }^{11}$ Note that $P_{t}^{M} \leq 0$.

${ }^{12}$ Note that $P_{t}^{H^{*}}$ refers to the first-best shadow value of energy-efficiency knowledge, while $\hat{P}_{t}^{H}$, discussed earlier, refers to the valuation of the knowledge stock in other, unmodeled research sectors.
} 
The term in square brackets in this expression adjusts the marginal product of research spending for (i) the intertemporal research spillover $\left(P_{t}^{H} \neq P_{t}^{H^{*}}\right)$, (ii) the inter-firm research spillover $(1-\ell)$, and (iii) the duplication externality $(b<1)$. The last term reflects the opportunity cost of crowding out in non-energy R\&D sectors. We note that the sub-optimal value of $P_{t}^{H}$ required in (41) is not the BAU value but rather the value obtained from the firms' firstorder condition (39) in the decentralized first-best optimum. Since the first-best values of other variables are known from the planner's problem, it is a simple matter to solve (39) for $P_{t}^{H}$.

We also use the model of the decentralized economy in the second-best scenario. In this case, the policy maker chooses the time path of the carbon tax to maximize welfare in the absence of a tailored $\mathrm{R} \& \mathrm{D}$ subsidy $\left(z_{t}=0\right)$. Specifically, the problem is to maximize (18) with respect to the flow variables $C, E N, F, R, Y, I, F O R C E$, the stock variables $K, H, C m, M A T, M U$, $M L, T E, T L$, and the time path of the carbon tax, $\tau$, subject to (i) structural constraints (1) - (16), (19'), (ii) BAU first-order conditions (23), (24), (25), (28), (30), (37), (38), (39), (iii) initial values of the stocks, (iv) non-negativity constraints on all the variables, (v) T given, and (vi) endogenous terminal stock values. As before, the non-negativity constraints do not come into play, the initial stocks and final horizon $\mathrm{T}$ are given, and the transversality conditions (36) yield terminal shadow prices equal to zero. We solve this maximization numerically rather than analytically. We also assume that carbon tax revenues are returned to agents in a lump-sum manner. As a consequence, the structural equation (6) applies, as the terms $\tau_{t} F_{t}$ and $G T_{t}$ cancel out in $\left(6^{\prime}\right)$. Nonetheless, individual agents do adjust their fuel consumption at the margin, in response to the carbon tax; thus $\tau_{t}$ enters into the first-order condition (37) which characterizes the fuel market.

\section{Parameters and initial values}

Table 2 shows our parameter values and the initial values of the variables. Initial values of variables $Y_{1}, K_{1}, L_{1}, F_{1}, M A T_{1}, M U_{1}, M L_{1}, T E_{1}$, and $T L_{1}$ correspond with world values in 2005 (Nordhaus 2008), while $C m_{1}$ is by definition zero. The damage and climate parameters $\xi, b_{11}, b_{21}$, $b_{12}, b_{22}, b_{32}, b_{33}, b_{23}, C_{1}, C_{2}, C_{3}$, and $C_{4}$ are also taken from Nordhaus $2008 .{ }^{13}$ For the fuel price parameters $\omega_{1}, \omega_{2}, \Omega$, and $P_{1}$, we use the values in Popp (2004).

\footnotetext{
${ }^{13}$ The initial values and parameters corresponding with Nordhaus (2008) are provided in documentation on Nordhaus' website http://nordhaus.econ.yale.edu .
} 
The initial value of $R_{1}$ is based on three values: (1) world output, (ii) the world average expenditure on R\&D as a percentage of GDP, and (iii) a scaling factor representing the share of energy $R \& D$ in total $R \& D$ expenditure. The first value corresponds with our measure of $Y_{l}$. The second value has been estimated by the World Bank at 2.04 percent in 2005. For the third value, we use 2 percent, following Popp (2003, 2006). Multiplying these three values yields our estimate of $R_{1}=\$ 25$ billion.

Capital's share in gross output, $\alpha$, is estimated to be 0.28 , based upon a before-tax rate of return on corporate bonds, $i$, of 4.5 percent (Boardman et al. 2006, p.249), an annual depreciation rate of capital, $\delta_{K}$, of 10 percent, and the initial values of $K$ and $Y$, i.e. $K_{1}=\$ 137$ trillion and $Y_{1}=\$ 61.1$ trillion. ${ }^{14}$ Labour's share in gross output, $\beta$, is estimated to be 0.60 based on the average share of labour income in U.S. GDP during 2005-2008. ${ }^{15}$ Energy's share of gross output is thus $(1-\alpha-\beta)=0.12$. In the case of Cobb-Douglas production, we then solve $\left(1^{\prime}\right)$ and (6) for $A_{1}{ }^{16}$

In the case of CES production, we assume an elasticity of substitution, $\sigma$, of 0.4 , which yields a value of $\gamma=-1.5$ according to the formula $\sigma=1 /(1-\gamma)$. Our elasticity value is roughly the mid-point of van der Werf's (2008) range of estimates for twelve countries and seven industries over the period 1978-1996. It is also the value used by Gerlagh (2008), for his upper nest of value-added (KL) and energy, and by Manne et al. (1995).

We set $\ell=0.75$ and crowdout $=0.5$, following Popp (2004). ${ }^{17}$ Regarding $b$, Popp (2004) and Gerlagh (2008) assume a value of 0.2, which entails rather extensive duplication of research effort. In contrast, based on indirect empirical evidence, Jones and Williams (2000) argue for a lower-bound value of 0.5 . In order to test the impact of this parameter, we consider low and high values of $b=0.2$ and $b=0.7$. Combining $b$ with $\ell$, we obtain the value of the opportunity cost parameter $\psi$ from (22). For $\phi$, lacking any empirical guidance, we perform

\footnotetext{
${ }^{14}$ We estimate capital's share as $\alpha=\left(i+\delta_{K}\right) K_{1} / Y_{1}$.

15 Data for this calculation are from the Bureau of Economic Analysis (www.bea.gov), tables "Gross Domestic Income by Type of Income" and "Gross Domestic Product." Total labour income is estimated as the sum of "compensation of employees, paid" and $1 / 2 \times$ "proprietors' income". The latter adjustment is intended to exclude payments to proprietors' capital.

${ }^{16}$ We treat $E N$ as the residual in our share calculations above because we do not have a price estimate for $E N$ which embraces both fossil fuels and energy-related human capital. In contrast, Popp (2004) estimates energy's share as the proportion of initial output spent on fossil fuels alone, a value of approximately 0.07 . But this approach attributes no payoff to energy-related human capital.

${ }^{17}$ Both Popp (2004) and Gerlagh (2008) assume firms are able to appropriate only 25 percent of the total benefits of their R\&D.
} 
sensitivity analysis at values $\phi=(0.5,0.0,-0.5)$. Popp (2004) uses $\phi=0.55$, based on calibration.

Following Nordhaus (1994), we assume a pure rate of time preference of 3 percent per annum $(\theta=0.03)$, which is similar to the value of 3.5 percent employed by Gerlagh (2008).

The choices of the remaining values $-H_{1}, E N_{1}, \alpha_{K}, \alpha_{L}, A_{1}, \eta, \Phi_{t}, \alpha_{K}, \alpha_{H}, \rho, a-$ are discussed in the Appendix, as well as further comments on the pure rate of time preference $\theta$.

\section{Results}

\section{Policy experiments}

We employ Popp's difference-in-difference metric for summarizing the welfare gain of induced innovation. The first difference refers to the improvement in welfare resulting from the optimal environmental policy, with R\&D held constant, compared with BAU. The second difference refers to the change in this welfare gain which results from adding induced R\&D to the model. In particular, the change in welfare is calculated as

$$
\Delta^{2} W \equiv \Delta(\Delta W)=\left[\frac{\left(W_{\text {end }, o p}-W_{B A U}\right)}{\left(W_{\text {exg }, o p}-W_{B A U}\right)}-1\right] \times 100
$$

where $W_{\text {end }, o p}$ represents the welfare value (equation 18) under optimal policy with endogenous (induced) technical change, $W_{\text {exg }, o p}$ represents the welfare value under optimal policy with exogenous technical change ( $R_{t}$ constrained to the BAU level), and $W_{B A U}$ represents welfare in the BAU scenario. This metric gives an assessment of the incremental welfare attributable to induced R\&D in the optimal environmental policy. ${ }^{18}$

We undertake six policy experiments to test the effects of different combinations of assumptions. The details are as follows and are summarized in Table 3.

\section{Experiment 1}

The first experiment measures the welfare gain attributable to induced innovation (42) in moving from BAU to the first-best optimal policy (carbon tax and R\&D subsidy). Production is assumed to be CES, with $\sigma=0.4$. The initial research expenditure $R_{1}=\$ 25$ billion. The opportunity cost of crowded-out research is measured on the assumption that $\hat{P}^{H}=P^{H}$

\footnotetext{
${ }^{18}$ In fact, Popp bases his measure of $\Delta^{2} W$ on discounted consumption, rather than $W$. Fussel (2007) shows that this can lead to important inconsistencies, and therefore we base our measure on $W$.
} 
(condition 22) - i.e. the shadow value of the crowded-out knowledge stock is insensitive to the internalization of spillovers and external effects. We start with this assumption since it is implicit in other single-knowledge-stock models that account for crowding out (e.g. Popp 2004, Bosetti et al. 2006).

\section{Experiment 2}

Experiment 2 differs from Experiment 1 in assuming Cobb-Douglas production $(\sigma=1)$. The other assumptions of Experiment 1 are retained (comparison of first-best with BAU, $R_{1}=\$ 25$ billion, and $\hat{P}^{H}=P^{H}$ ).

\section{Experiment 3}

Experiment 3 differs from Experiments 1 and 2 by considering the possibility that the social value of new knowledge capital, $\hat{P}^{H}$, in unmodeled research sectors is not the same as the perceived value, $P^{H}$. This issue is important since a firm's shadow value of knowledge capital is likely to be different in the presence of appropriately chosen policy instruments, leading to internalization of spillovers and external affects, than in the absence of such policy measures. Differences between $\hat{P}^{H}$ and $P^{H}$ lead to revised estimates of the opportunity cost of crowding out, as shown in (22).

Gerlagh (2008) indicates that there is much more complexity in the interactions between R\&D sectors than is typically accounted for in single-knowledge-stock models. Two points are salient here. First, while non-energy R\&D may be crowded out in some sectors, it may be stimulated in others, depending upon whether the associated good or activity is a substitute or complement to fossil fuel consumption. For example, an abatement policy that makes fossil fuels more expensive may increase R\&D in energy efficiency (substitute for fossil fuels), decrease $R \& D$ in fossil fuel production (complement with fossil fuels), and increase R\&D in advanced materials (substitute for fossil fuels and energy generally). Second, the social valuation of nonenergy R\&D depends in part upon an interaction between the environmental externality and the demand for the associated good or activity. In general, an agent's valuation of R\&D that is complementary to fossil fuels will be overestimated if the environmental externality has not been taken into account - i.e. $P^{H}>\hat{P}^{H}$ - while an agent's valuation of substitutes to fossil fuels will be underestimated in these circumstances - i.e. $P^{H}<\hat{P}^{H}$.

Taken together, these two points suggest that climate policies such as a carbon tax and R\&D subsidies for energy efficiency improvements will crowd out relatively low-value $R \& D$ 
activities (complements of fossil fuels) and stimulate relatively high value $R \& D$ activities (substitutes of fossil fuels). These patterns find empirical support in Popp and Newell's (2012) study of firm-level R\&D spending and patents. Since we assume that spillovers and externalities have not been internalized in unmodeled research sectors, it follows that estimating the net opportunity cost of crowding out based on the assumption of $\hat{P}^{H}=P^{H}$ in (22) yields a value that is too high (i.e. the effect of R\&D that is crowded out net of the benefit of $R \& D$ that is stimulated by the climate policy). Instead, we must consider $\hat{P}^{H}<P^{H}$ for crowded-out R\&D. For the purpose of Experiment 3, we consider $\hat{P}^{H}$ equal to $1 / 2$ the value of $P^{H}$, which yields similarly reduced values of $\psi$ in (22). In fact, the true balance of R\&D crowded out and R\&D stimulated may reveal an even lower net social value of opportunity cost from crowding out, with values in the range of $\hat{P}^{H} \leq 0$. A negative value in this case would reflect an overall benefit from the crowding out / stimulation effects of energy R\&D.

Apart from this change, we retain the assumptions of Experiment 1, in particular (i) comparison of first-best optimal policy (carbon tax and R\&D subsidy) with BAU, (ii) CES production $\left(\sigma=0.4\right.$ ), and (iii) $R_{1}=\$ 25$ billion.

\section{Experiment 4}

Experiment 4 tests the sensitivity of our results to $R_{1}$, the initial value of energy efficiency R\&D. As discussed above, our base assumption, following World Bank estimates of R\&D spending and Popp $(2003,2006)$, is that $R_{1}$ is equal to 0.0408 percent of world output $\left(Y_{1}\right)$. In contrast, Gerlagh (2008) assumes $R_{1}$ is equal to approximately 0.63 percent of world output. Using this assumption, we have $R_{1}=0.0063 \times Y_{1}=\$ 384.9$ billion, roughly 15 times our base value of $\$ 25$ billion. We calibrate the model to the larger value of $R_{1}$ in this experiment ( $\$ 384.9$ billion), and assess the impact on the welfare measure (42). All other assumptions from Experiment 1 are retained, i.e. (i) comparison of first-best optimal policy with BAU, (ii) CES production $(\sigma=0.4)$, and (iii) $\hat{P}^{H}=P^{H}$.

\section{Experiment 5}

Experiment 5 measures the welfare gain (42) in moving from BAU to the second-best climate policy consisting of an optimally chosen carbon tax without an $R \& D$ subsidy. This experiment is intended to capture the possibility that a differentiated subsidy for energy efficiency $R \& D$ - as opposed to a uniform subsidy for all forms of R\&D - may be politically or 
administratively infeasible. The remaining assumptions are based on Experiment 1, i.e. CES production $(\sigma=0.4), R_{1}=\$ 25$ billion, and $\hat{P}^{H}=P^{H}$.

\section{Experiment 6}

Experiment 6 presents a combination of Experiment 5 and Experiment 3, i.e. a comparison of BAU and second-best policy (carbon tax) with $\hat{P}^{H}=\frac{1}{2} P^{H}$. Production is CES $(\sigma=0.4)$ and $R_{1}=\$ 25$ billion.

\section{Overview results}

We begin by presenting the solution paths for output $(Y)$, consumption $(C)$, carbon emissions / fuel use $(F), \mathrm{R} \& \mathrm{D}$ expenditure $(R)$, average temperature change (atmosphere and upper ocean) (TE), carbon tax $(\tau)$, and the research subsidy $(z)$ corresponding with BAU and the first-best from Experiment 1 and with the second best (selected variables) from Experiment 5. These results set the scene for the following section, in which we focus more narrowly on the contribution of induced innovation.

Figure 1 shows output and consumption per capita for BAU, in Experiment 1, under the assumptions of $\phi=0.5$ ("standing on the shoulders") and $b=0.7$ (modest duplication externality), over the 140 year interval 2005-2145. These paths exhibit the standard growth pattern attributable to capital accumulation, exogenous technical change, and induced innovation. The results for BAU based on other combinations of $\phi$ and $b$ differ in terms of levels but not pattern.

Figure 2 presents the first-best path of output relative to BAU, in Experiment 1, for the six different combinations of $\phi$ and $b$ which were tested. The most striking feature is the sharp differentiation between results based on $b=0.7$ (modest duplication externality) and $b=0.2$ (large duplication externality). Among results based on $b=0.7$, there is no sacrifice in output in the first-best in order to control the environmental externality. Indeed, the three time paths in this group show first-best output growing slowly but steadily over time, compared with BAU, reaching levels $1.0-1.5$ percent higher by 2100 . In contrast, the three time paths based on $b=0.2$ exhibit a small but persistent reduction in output in the first-best (less than one percent), compared with BAU, which lasts until 2080. By 2100 , these paths are only marginally above the BAU level. In addition, these paths are indistinguishable from each other; i.e. differences in $\phi$ have no impact. The role of $\phi$ is more important when $b$ is large $(b=0.7)$, but it is still 
secondary to the influence of $b$; i.e high $b$ and low $\phi$ yield a significantly higher growth pattern than low $b$ and high $\phi$.

One interpretation of these results is that they reflect the productivity of research spending in creating new knowledge capital. When research spending is productive (high $b$ ), the accumulation of knowledge capital offers an efficient avenue for addressing the environmental externality. In addition, the internalization of knowledge spillovers through research subsidies in the first-best removes an important distortion in the economy independent of the environmental externality. In contrast, when research spending is less productive (low $b$ ), the accumulation of knowledge capital is more costly, regardless of the scale of the inter-temporal knowledge spillover $(\phi)$. In that case, accumulation of knowledge capital is less competitive with other options for addressing the environmental externality, such as reducing output, which we see in the case of $b=0.2$ in Figure 2.

However, this interpretation doesn't go far enough. In particular, we know from (22) that the social marginal product of research spending reflects the opposing effects of the duplication externality and inter-firm knowledge spillovers. In the case of the high duplication externality $(b=0.2)$, we observed earlier that BAU results in too much research spending, as the marginal product $(0.8$ in Table 1 , corresponding with $b=0.2$ and $\ell=0.75)$ is less than the marginal cost of the spending. It follows that first-best policy means reducing R\&D, compared with BAU, rather than increasing it. As a result, in this case, the accumulation of knowledge capital plays no role at all in mitigating the environmental externality as the economy moves away from BAU, except as a source of funding which can be reallocated to more efficient uses.

This result is reflected in negative values of the R\&D subsidy paid in the first best, in Experiment 1 , when $b=0.2$. Table 4 shows the average value of R\&D subsidy paid during 2005-2100 for the six test combinations of $\phi$ and $b .{ }^{19}$ For the three cases with $b=0.2$, the subsidy is in the range of negative 12 to negative 13 percent, i.e. a tax on $R \& D$, in order to counteract the overspending exhibited under BAU. In contrast, for the three cases with $b=0.7$, the R\&D subsidy ranges from positive 30 to 35 percent. In these cases, the inter-firm knowledge spillover dominates the duplication externality in BAU, and therefore positive values of subsidy are required to encourage additional R\&D spending in the first best.

\footnotetext{
${ }^{19}$ The per-period values of the subsidies turn out to be almost constant during this interval.
} 
The opportunity to reallocate funding from excessive R\&D spending under BAU when $b=0.2$ makes it possible to maintain consumption spending close to BAU levels (even marginally above in some periods) while pursuing output reductions in 2005-2080 in order to reduce emissions. Figure 3 shows this result. For the three cases with $b=0.2$, first-best consumption is marginally higher than the BAU level in 2005-2020. It then falls slightly below the BAU level from 2020-2060 before moving permanently higher thereafter. Meanwhile, the reductions in output for these three cases, shown in Figure 2, are larger, start immediately, and last twenty years longer - to 2080 .

The consumption trends for the three cases with $b=07$ reflect the more conventional pattern for first-best emissions reduction. As shown in Figure 3, consumption is reduced slightly for the first 40 years in these cases (maximum reduction from BAU of 0.18 percent), after which the payoff from increased human capital and reduced emissions translates into increased consumption.

The second-best paths for consumption in Experiment 5, under both high and low duplication ( $b=0.2$ and $b=0.7$ ), are essentially identical to the first-best paths for high duplication $(b=0.2)$, and therefore we have not shown them separately in Figure 3 . The similarity between second-best consumption paths and first-best with high duplication follows from the limited role that induced technical change plays in climate policy under both approaches. In the second best, the absence of targeted subsidies means that energy-efficiency R\&D is only stimulated indirectly by the carbon tax, while knowledge spillovers remain unaddressed. Similarly, in the first-best with high duplication, induced innovation plays no direct role in climate policy, as discussed above.

An important result revealed in Figure 3 is that sacrifices in consumption made by early generations under climate policy are extremely minor. Under second-best and first-best with high duplication $(b=0.2)$, the largest reduction in consumption, compared with BAU, is 0.05 percent in 2030-2040 - essentially zero. Early sacrifices are greater under first-best with low duplication $(b=0.7)$, but the payoffs in terms of future consumption are also much higher, as shown in the figure. The largest sacrifice in this case occurs in 2010-2020; but at only 0.18 percent, this sacrifice remains barely significant. These results support Rezai's (2011) argument that the conventional view of climate policy entailing an upfront cost is largely an artifact of poor 
handling of the BAU scenario. In Figure 3 we see that, with BAU modeled correctly, there appears to be no major sacrifice associated with optimal climate policy.

The patterns of R\&D expenditure are presented next. Figure 4 compares the paths of research expenditure between BAU, first-best, and second-best for $\phi=0.5$ and $b=0.7$, which we take as representative for cases with low duplication externality. ${ }^{20}$ Here we see a significant increase in R\&D expenditure in the first-best, compared with both BAU and the second best. In 2005 , first-best R\&D is equal to $\$ 85.8$ billion, compared with $\$ 26.8$ billion for the second-best and $\$ 25.0$ billion for BAU - i.e. first-best R\&D is more than three times BAU R\&D in this period - and the gap between the first-best and other two scenarios grows over time in dollar terms. This result reflects the importance of highly productive investments in energy efficiency knowledge capital as a means to reduce greenhouse gas emissions, as well as the effectiveness of R\&D subsidies in internalizing inter-firm and inter-temporal knowledge spillovers. In contrast, the second-best scenario exhibits only slight increases in R\&D expenditure over the BAU level, reflecting the absence of subsidies to internalize the knowledge spillovers.

Figure 5 compares the paths of research expenditure for $\phi=0.5$ and $b=0.2$, which we take as representative for cases with high duplication externality. Here we see a complete reordering of patterns compared with the previous case. First, we have already noted that the BAU scenario exhibits overspending on $\mathrm{R} \& \mathrm{D}$, as the duplication externality dominates the knowledge spillovers. As a result, the first-best path of research spending is everywhere lower than BAU although the differences are modest, starting at approximately 8 percent in 2005 (\$2 billion) and declining thereafter in percentage terms (increasing slightly in dollar terms). The more striking result is that the second-best path of R\&D exceeds both BAU and first-best. But of course, this result reflects the absence of a tax on $R \& D$ in the second-best to control overspending. Compounding the problem, the second-best carbon tax increases the cost of the fuel input, which induces agents to invest even more in energy-efficiency knowledge, despite the inefficiency of this option.

Figures 6 and 7 present the trends on carbon emissions / fuel use. Figure 6 shows emissions in the first-best for the six test combinations of $\phi$ and $b$. Once again, we see the sharp differentiation of cases with $b=0.7$ and cases with $b=0.2$. As discussed, the higher value of $b$

\footnotetext{
${ }^{20}$ The first-best path is taken from Experiment 1, the second-best path from Experiment 5, and the BAU path is common to both experiments.
} 
(reduced duplication) translates into a lower cost of generating new energy-efficiency knowledge, and therefore it is easier to substitute away from carbon based fuels.

Figure 7 compares the emission trends between BAU, first-best and second-best for the case of $\phi=0.5$ and $b=0.7$. Both first and second best yield significant reductions in emission compared with BAU. In 2005, first-best emissions are 6 percent lower than BAU ( $0.5 \mathrm{Gt} \mathrm{C}$ ), and this gap grows to 25 percent ( $4 \mathrm{Gt} \mathrm{C}$ ) by 2100 . First-best and second-best yield virtually identical emissions trends. However, notwithstanding their near equality, it is interesting to note that, with the exception of the first period, the first-best yields fractionally higher emissions than the second best. This is an interesting demonstration of the different trade-offs in these two scenarios. With knowledge spillovers internalized, the first-best relies slightly more on investments in knowledge capital to support consumption while the second best relies slightly more on attenuating the environmental externality through emissions restraint.

The reductions in emissions translate in a symmetric manner into reductions in atmospheric concentration of carbon and ultimately, through the climate model, into reductions in the growth trend of world average temperature. As an example, Figure 8 presents the results on temperature for BAU, first-best and second-best in the case of $\phi=0.5$ and $b=0.7$. Note that, although the growth trend is reduced due to emissions restraint, the model does not result in the stabilization of global temperature which is frequently suggested as a climate policy goal (as for example under the United Nations process on climate change). Rather, the estimation of the damage function (7), as well as the choice of time preference, $\theta$, are such that only attenuation of the growth of emissions and temperature are warranted rather than stabilization. Nordhaus (2008) provides an extended discussion of this topic.

Figure 9 presents the carbon tax profiles corresponding with first and second best for the combinations $(\phi=0.5, b=0.7)$ and $(\phi=0.5, b=0.2)$. We take the first combination as representative of cases with low duplication externality $(b=0.7)$ and the second as representative of cases with high duplication externality $(b=0.2)$. The main lesson of the figure is that, from the second period onwards, second best carbon taxes are larger than first best taxes. This result follows from the greater efficiency of the first-best scenarios. When $b=0.7$, the firstbest scenario relies more on investments in knowledge capital to support consumption while the second best relies more on attenuating the environmental externality. Conversely, when $b=0.2$, the first-best scenario benefits from the reallocation of excessive R\&D spending to support 
consumption, and therefore less control of the environmental externality is desired than in the second best.

Table 5 presents the carbon taxes for 2005, the only period for which the first-best taxes exceed the second-best. This ordering of the taxes follows from the combination of discounting and increased efficiency under the first-best scenarios. Greater efficiency means that the firstbest scenarios are better able to make up for sacrifices in the first period, despite the effects of discounting, with higher consumption at lower cost in the future. In contrast, the second best scenarios are less effective at clearing the required rate of return on investment and therefore favour first-period outcomes through lower carbon taxes, among other things.

\section{Contribution of induced innovation}

We now turn our attention to the contribution of induced innovation to climate policy. For Experiments 1 - 6, we calculate the welfare gain attributable to induced innovation (42), for each of the six test combinations of $\phi$ and $b$. The results are presented in Table 6. Note that (42) measures the increase in welfare gain that is achievable by introducing induced innovation into the model, compared with a baseline involving exogenous technical change, rather than the level of the welfare change due to climate policy. The results in the table highlight the importance of assumptions regarding the duplication externality, the elasticity of substitution of productive inputs, the opportunity cost of crowding out non-energy R\&D, the initial level of R\&D spending, and the difference between first-best and second-best climate policy.

Perhaps the most important result to emerge from the Table is the sharp differentiation between cases with low duplication externality $(b=0.7)$ and those with high duplication $(b=0.2)$. In all experiments, the results with low duplication are multiple orders of magnitude larger than those with high duplication. This outcome is not surprising, given what we observed in the overview results. In particular, low duplication translates into low cost of acquiring new energy efficiency knowledge. Therefore, introducing induced technical change adds an important mechanism into the model through which agents can respond to climate policy. In contrast, as discussed above, induced R\&D plays no direct role in climate policy when duplication is high $(b=0.2)$. Therefore, introducing induced technical change into the model, in this case, does not add a new avenue for controlling greenhouse gas emissions. Experiment 1 provides a good example of this outcome, with an average $\Delta^{2} W$ value of 98.7 percent for $b=0.7$ and 0.09 
percent for $b=0.2$; i.e. adding induced technical change to the model almost doubles the welfare gain of climate policy when duplication is low but barely increases it when duplication is high.

In contrast, variation in $\phi$ is of lesser importance than variation in $b$. In all six Experiments, variation in $\phi$ between -0.5 and 0.5 , holding $b$ constant, leaves $\Delta^{2} W$ values within the same order of magnitude. In contrast, variation in $b$ from 0.2 to 0.7 , holding $\phi$ constant, results in changes in $\Delta^{2} W$ of multiple orders of magnitude. The relative importance of the parameters might be reversed for more extreme values of $\phi$. However, the values we have chosen are consistent with existing literature. In particular, Jones (1995) argues that values of $\phi \geq 1$ are not consistent with the empirical trends on productivity growth and employment shares in R\&D.

Comparing Experiment 1 with Experiment 2 indicates that, for low duplication $(b=0.7)$, the contribution of induced innovation is quite sensitive to the elasticity of substitution among capital, labour, and energy in production. For the relatively inelastic case of $\sigma=0.4$ (Experiment 1), we observe an average $\Delta^{2} W$ value of 98.7 percent, when $b=0.7$. In contrast, for the more elastic case of $\sigma=1.0$ (Experiment 2), we observe an average $\Delta^{2} W$ value of 41.9 percent, when $b=0.7$. This result is not surprising, since greater elasticity makes it easier to substitute physical capital, $K$, when the price of $E N$ increases, and therefore less energy-efficiency knowledge is required. Similar results emphasizing the importance of substitution elasticities are obtained by Sue Wing (2006), Shittu and Baker (2010), Acemoglu et al. (2012), and Gans (2012). In contrast, when duplication is high $(b=0.2)$, energy-efficiency capital does not play a direct role in climate policy, and therefore the difference between exogenous and endogenous technical change is negligible.

The comparison of Experiments 1 and 3 reveals the importance of assumptions regarding the opportunity cost of crowding out non-energy R\&D through climate policy. The results in Experiment 1 are based on the assumption that the value of non-energy R\&D is not sensitive to environmental externalities or knowledge spillovers (i.e. $\hat{P}^{H}=P^{H}$ ), whereas Experiment 3 assumes that energy-efficiency $R \& D$ crowds out relatively low value $R \& D$ in non-energy sectors (i.e. $\left.\hat{P}^{H}=\frac{1}{2} P^{H}\right)$. When duplication is low $(b=0.7)$, Experiment 3 shows a much higher contribution of induced innovation - an average $\Delta^{2} W$ value of 436.8 percent compared with 98.8 percent in Experiment 1. Even when duplication is high $(b=0.2)$, Experiment 3 returns an 
average $\Delta^{2} W$ value of 1.4 percent, which is more than fifteen times higher than in Experiment 1 (0.09 percent). In this case, $R \& D$ is even more over-supplied in BAU due to the lower opportunity cost. Therefore, there is more excess $R \& D$ to reallocate to consumption in the firstbest. These results help to explain the divergence of results in earlier literature, as for example between Popp (2004) and Gerlagh (2008). Popp assumes a high social valuation of crowded-out $\mathrm{R} \& \mathrm{D}$ in non-energy sectors (combined with high duplication at $b=0.2$ ) whereas Gerlagh accounts for crowding out relatively low-value activities in fossil-fuel production research.

The comparison of Experiments 1 and 4 reveals the sensitivity of the contribution of induced innovation to $R_{1}$, the initial value of energy-efficiency R\&D. Experiment 4 assumes that $R_{1}$ is 15.4 times the base value employed in Experiment 1 (see the discussion of the experiments above). As a result, when duplication is low ( $b=0.7)$, Experiment 4 returns an average $\Delta^{2} W$ value of 324.7 percent - more than three times larger than the value in Experiment 1 (98.7 percent). Even when duplication is high $(b=0.2)$ and energy-efficiency knowledge accumulation does not play a direct role in climate policy, Experiment 4 returns an average $\Delta^{2} W$ value that is two orders of magnitude greater than Experiment 1 (2.07 percent vs. 0.09 percent respectively). These results indicate that the cost of holding an input fixed, in terms of forgone production, is higher for inputs that account for a greater share of GDP. In a loose sense, an input with a higher GDP share is more important in the production process, and therefore the cost of failing to choose it optimally is also greater. Hence the contribution of induced innovation is greater when $R_{1}$ is greater.

Clearly the difference in $R_{1}$ between Experiments 1 and 4 has a significant impact upon our measurement of the contribution of R\&D to welfare improvement under first-best policy. On the surface, it appears that our base assumption on $R_{1}$ is probably closer to the right order of magnitude than Gerlagh's (2008) approach, as it has a more explicit empirical basis. However, there is still room for improvement. Indeed, we have reason to believe that the true value of $R_{I}$ may be even lower than 0.0408 percent of world output, since Popp's $(2003,2006)$ discussion of the data refers simply to "energy R\&D" which presumably aggregates both energy efficiency $\mathrm{R} \& \mathrm{D}$ and energy production R\&D. Clearly this is a matter that merits further inquiry.

The comparison of Experiments 1 and 5 indicates that the welfare impact of induced innovation is significantly greater in the first-best - i.e. when a research subsidy (tax) is used to internalize distortions in knowledge acquisition - than in the second best, provided that 
duplication is low $(b=0.7)$. Under this assumption, the average $\Delta^{2} W$ value shown in the first best (Experiment $1-98.7$ percent) is nearly eight times the average value shown in the second best (Experiment $5-12.5$ percent). In contrast, when duplication is high $(b=0.2)$, the role of energy-efficiency knowledge capital is not great in the first best, and therefore the difference in the value of $\Delta^{2} W$ between first-best (Experiment 1) and second-best (Experiment 5) is negligible.

Experiment 5 reveals curious negative results for $\Delta^{2} W$ under $b=0.2$. In other words, adding induced technical change to the model makes people worse off, compared with exogenous technical change, in the second-best scenario with high duplication. Upon reflection, this result can be explained by the combination of second best climate control and excessive research spending in BAU when $b=0.2$. Exogenous technical change preserves the excessive BAU level of research spending, but at least it doesn't make it worse. In contrast, induced technical change leads private agents to make things worse by increasing research spending further, in response to higher carbon fuel prices. Instead, first-best policy requires that research spending be reduced from BAU levels, through the application of a tax on excessive research spending (Experiment 1). This result highlights that, in the second best, greater flexibility of agents to respond to policy signals is not always a good thing, although, in the present case, the induced worsening of welfare, at less than half of one percent, is minor.

Experiment 6 presents a variation on the second-best story in which energy-efficiency R\&D crowds out relatively low value R\&D in other (unmodeled) sectors, i.e. $\hat{P}^{H}=\frac{1}{2} P^{H}$. In this case, the opportunity cost of crowded-out R\&D is half the value in Experiment 5, following (22). Private agents continue to ignore the duplication externality, knowledge spillovers, and the opportunity cost of crowded out research, as discussed in Section II. Therefore, the first-order conditions for BAU remain the same as in Experiment 5. In the case of high duplication ( $b=$ 0.2 ), agents continue to over-invest in energy-efficiency $R \& D$, and the second-best climate policy exacerbates this over-investment, by failing to send the correct signals regarding research spending. However, the cost of this over-investment is lower than in Experiment 5, due to the reduced cost of crowding out. As a result, the welfare impact of induced innovation is positive even under high duplication (average $\Delta^{2} W$ value of 0.8 percent). Under low duplication ( $b=$ 0.7 ), we see that the reduced opportunity cost results in an increase in the $\Delta^{2} W$ value of induced 
innovation of roughly 10 percentage points for Experiment 6 compared with Experiment 5 (average values of 22.3 percent and 12.5 percent respectively).

Overall, we find that Experiment 3 provides the most plausible assessment of the impact of induced R\&D for first-best policy and Experiment 6 provides the most plausible assessment for second-best policy. Both of these scenarios assume that R\&D crowded out in other sectors is of relatively low social value, due to the failure of agents in these sectors to take account of related environmental externalities (e.g. R\&D in fossil energy production as argued by Gerlagh (2008)). If duplication is low, as suggested by Jones and Williams (2000), then these Experiments indicate that induced $R \& D$ can make a significant contribution to climate policy, with a four- to five-fold increase in the welfare impact under first-best policy (Experiment 3 ) and a $20-24$ percent increase under second best (Experiment 6).

Whether differentiated research subsidies (and therefore first-best policy) are feasible is an important question. We are sympathetic to the arguments of Hart (2008) and Gerlagh et al. (2009) to the effect that differentiated subsidies require too much detailed information to be feasible. However, we also note that, to date, some governments (e.g. Canada and the United States) have relied on nothing but clean-energy research subsidies for climate policy. Perhaps it is more accurate to say that precisely tailored research subsidies are infeasible while less carefully chosen subsidies pose no problem.

\section{Conclusion}

A number of important lessons have been learned from the sensitivity analysis which we have presented with our single-knowledge-stock model of R\&D, growth and climate. Perhaps the most central result is the great importance of the duplication externality in determining the significance of induced R\&D in climate policy. With low duplication, the inclusion of induced R\&D in the model leads to a significant improvement in the welfare impact of climate policy. This result is noteworthy, since the only empirically based source which we have found on this topic - Jones and Williams (2000) - indicates that duplication is indeed likely to be in the low range. In contrast, when duplication is high, induced innovation is simply not important in climate policy, as the cost of acquiring new knowledge capital is high and agents over-allocate resources to research in business-as-usual anyway. Previous papers in the climate policy 
literature have not captured this effect as they have internalized duplication in business-as-usual rather than treating it as an externality.

Conditional upon low duplication, we identify a number of other factors which play an important role in determining the impact of induced R\&D. First, the feasibility of dedicated subsidies for energy-efficiency R\&D makes it possible to implement a first-best policy regime, in which both the subsidies and a carbon tax focusing on the climate externality are chosen optimally. Under such a regime, conditional on low duplication, we find the welfare contribution of induced $R \& D$ is roughly eight times greater than under a second-best regime consisting of a carbon tax only. This difference speaks to the scale of inter-firm knowledge spillovers as a major distortion in the economy.

Second, opportunity cost is a major factor in the contribution of induced R\&D, and accounting for distortions in the measurement of opportunity cost is essential. Loosely speaking, the issue is whether we assume new energy-efficiency R\&D crowds out research in other sectors which has roughly equivalent social value, or whether it crowds out research in relatively lowvalued sectors. In our model, we compare equivalent value and half-value for the opportunity cost of crowded-out R\&D. Conditional upon low duplication, we find that half-value for the opportunity cost quadruples the welfare impact of induced R\&D compared with full value. This result is significant, as previous empirical and modeling evidence suggests that crowding out low-value sectors is most likely.

Third, the initial level of R\&D expenditure creates a market size effect which has an important influence on the contribution of induced technical change. We compare an empirically based initial value of $R \& D$ with a value fifteen times greater, which has been used elsewhere in the literature. Conditional upon low duplication, we find that the larger value of initial R\&D yields a welfare impact of induced technical change which is more than three times greater. This result is instructive, since the lower, empirically based value of initial R\&D is itself probably too high, since it does not distinguish between energy-efficiency R\&D and energy-production R\&D. Further empirical work is merited in order to establish a credible measure of energy-efficiency R\&D.

Fourth, the elasticity of substitution between energy and other factors of production has an important influence on the contribution of induced R\&D. Conditional upon low duplication, we find that an empirically based low elasticity value (0.4) yields a welfare impact of induced 
R\&D in our model which is more than double than in the case of a unitary elasticity (CobbDouglas). This result is important since several models in the climate literature employ a CobbDouglas structure which is not consistent with most empirical evidence.

In contrast, we find that the direction and scale of the inter-temporal research spillover is of secondary importance compared with the other factors we tested. While a stronger spillover (more positive) always yields a higher welfare impact of induced $R \& D$, the value of the welfare impact is typically within the same order of magnitude for the plausible range of the spillover parameter.

Some of the insights we have obtained help to explain results in the literature, but some results in the literature remain difficult to interpret due to inappropriate handling of externalities in BAU. Our results provide strong support for Rezai's (2011) argument that, with BAU modeled appropriately (all externalities treated as external), sacrifices for early generations associated with optimal climate policy are minor and potentially even non-existent. 


\section{References}

Acemoglu, Daron (2002), “Directed Technical Change,” Review of Economic Studies 69(4), 781 809.

Acemoglu, Daron, Philippe Aghion, Leonardo Bursztyn, and David Hemous (2012), "The Environment and Directed Technical Change" American Economic Review 102(1), 131-166

Barr, J.R. and Manne, A.S., 1967. Numerical Experiments with Finite Horizon Planning Models. Indian Economic Review.

Boardman, Anthony E., David H. Greenberg, Aidan R. Vining, and David L. Weimer (2006). Cost-Benefit Analysis: Concepts and Practice, $3^{\text {rd }}$ ed. Pearson Prentice Hall.

Bosetti, Valentina, Carlo Carraro, and Marzio Galeotti (2006), "The Dynamics of Carbon and Energy Intensity in a Model of Endogenous Technical Change," in Ottmar Edenhofer, Carlo Carraro, Jonathan Kohler, and Michael Grubb, eds., Endogenous Technological Change and the Economics of Atmospheric Stabilisation, Special Issue of The Energy Journal, pp.191-205.

Buonanno, Paolo, Carlo Carraro, and Marzio Galeotti (2003), "Endogenous Induced Technical Change and the Costs of Kyoto," Resource and Energy Economics 25, pp. 11-34.

Edenhofer, Ottmar, Kai Lessmann, Claudia Kemfert, Michael Grubb, and Jonathan Kohler (2006), "Induced Technological Change: Exploring its Implications for the Economics of Atmospheric Stabilization: Synthesis Report from the Innovation Modeling Comparison Project," in Ottmar Edenhofer, Carlo Carraro, Jonathan Kohler, and Michael Grubb, eds., Endogenous Technological Change and the Economics of Atmospheric Stabilisation, Special Issue of The Energy Journal, pp.57-107.

Fischer, Carolyn and Richard G. Newell (2008), "Environmental and Technology Policies for Climate Mitigation," Journal of Environmental Economics and Management 55, 142-162

Fussel, H.-M. (2007), "Methodological and Empirical Flaws in the Design and Application of Simple Climate-Economy Models," Climatic Change 81, 161-185.

Gans, Joshua S. (2012), "Innovation and Climate Change Policy," American Economic Journal: Economic Policy 4(4), 125-145

Gerlagh, Reyer (2008), “A Climate-Change Policy Induced Shift from Innovations in CarbonEnergy Production to Carbon-Energy Savings," Energy Economics 30, pp. 425-448.

Gerlagh, Reyer, Snorre Kverndokk, and Knut Einar Rosendahl (2009), “Optimal Timing of Climate Change Policy: Interaction Between Carbon Taxes and Innovation Externalities," Environment and Resource Economics 43(3), 369-90 
Goolsbee, A., (1998), "Does Government R\&D Policy Mainly Benefit Scientists and Engineers," American Economic Review 88 (2), 298-302.

Goulder, Lawrence H., and Koshy Mathai (2000), "Optimal CO2 Abatement in the Presence of Induced Technological Change," Journal of Environmental Economics and Management 39(1), $1-38$.

Goulder, Lawrence H., and Stephen H. Schneider (1999), "Induced Technological Change and the Attractiveness of $\mathrm{CO}_{2}$ Abatement Policies," Resource and Energy Economics 21, 211-253.

Goulder, Lawrence H., and Lawrence H. Summers (1989), "Tax Policy, Asset Prices, and Growth: a General Equilibrium Analysis,” Journal of Public Economics 38, 265-296.

Hart, R. (2008), “The Timing of Taxes on CO2 Emissions When Technological Change is Endogenous," Journal of Environmental Economics and Management 55(2), 194-212.

Jaffee, Adam, Richard Newell, and Robert Stavins (2005), "A Tale of Two Market Failures: Technology and Environmental Policy,” Ecological Economics 54, 164-174.

Jones, Charles I. (1995), "R\&D-Based Models of Economic Growth," Journal of Political Economy 103(4), 759-84.

Jones, C.I., and J.C. Williams (2000), "Too Much of a Good Thing? The Economics of Investment in R\&D," Journal of Economic Growth 5, 65-85.

Laibson, D. (1997), "Golden Eggs and Hyperbolic Discounting," Quarterly Journal of Economics 112(2), 443-477.

Manne, A.S., R. Mendelsohn, and R. Richels (1995), "MERGE, a Model for Evaluating Regional and Global Effects of GHG Reduction Policies," Energy Policy 23, 17-34.

Massetti, Emanuele, and Lea Nicita (2010), "The Optimal Climate Policy Portfolio When Knowledge Spills Across Sectors,” FEEM Working Paper 96.2010.

McKibbin, Warwick J., and Peter J. Wilcoxen (1999), "The Theoretical and Empirical Structure of the G-Cubed Model," Economic Modeling 16, 123-148.

Newell, R.G., and W.A. Pizer (2003), "Discounting the Distant Future: How Much Do Uncertain Rates Increase Valuations," Journal of Environmental Economics and Management 46(1), 5271.

Nordhaus, William D. (1994). Managing the Global Commons: The Economics of Climate Change. MIT Press.

Nordhaus, William (2008). A Question of Balance: Weighing the Options on Global Warming Policies. Yale University Press. 
Nordhaus, William D., and Joseph Boyer (2000). Warming the World: Economic Models of Global Warming. MIT Press.

Popp, David (2006), "ENTICE-BR: The Effects of Backstop Technology R\&D on Climate Policy Models,” Energy Economics 28, 188-222.

Popp, David (2004), "ENTICE: Endogenous Technological Change in the DICE Model of Global Warming," Journal of Environmental Economics and Management 48, 742-768.

Popp, David (June 2003), "ENTICE: Endogenous Technological Change in the DICE Model of Global Warming," NBER Working Paper, No. 9762.

Popp, David (2002), "Induced Innovation and Energy Prices," American Economic Review 92, 160-180.

Popp, David, and Richard Newell (2012), "Where Does Energy R\&D Come From? Examining Crowding Out from Energy R\&D," Energy Economics 34, 980-991.

Rezai, Armon (2011), "The Opportunity Cost of Climate Policy: A Question of Reference," Scandinavian Journal of Economics 113(4), 885-903.

Rezai, Armon, Duncan K. Foley, and Lance Taylor (2012), “Global Warming and Economic Externalities," Economic Theory 49, 329-351.

Shiell, Leslie and Nikita Lyssenko (2008), "Computing Business-as-Usual with a Representative Agent and a Pollution Externality," Journal of Economic Dynamics and Control 32(5), 15431568.

Shittu, Ekundayo, and Baker, Erin (2010), "Optimal Energy R\&D Portfolio Investments in Response to a Carbon Tax," IEEE Transactions on Engineering Management 57(4), 547-559

Sue Wing, Ian (2006), “Induced Technological Change: Firm Innovatory Responses to Environmental Regulation.” (Working Paper, Boston University)

Summers, Lawrence H. (1981), "Taxation and Corporate Investment: a q-Theory Approach," Brookings Papers on Economic Activity 1981(1), 67-140.

van der Werf, Edwin (2008), "Production Functions for Climate Policy Modeling: An Empirical Analysis," Energy Economics 30, 2964-2979.

Weitzman, M. (2001), “Gamma Discounting,” American Economic Review 91(1), 260-271.

Wigley, T.M.L., R. Richels, and J.A. Edmonds (1996), "Economic and Environmental Choices in the Stabilization of Atmospheric CO2 Concentrations," Nature 379, 240-43. 
Ziagos, John P., and Gene Berry (September 18, 2006), "Visualizing Future $\mathrm{CO}_{2}$ and Energy Flows for the U.S. and World," Atmosphere, Earth and Energy Department, Energy and Environment Directorate, Lawrence Livermore National Laboratory. Available at $<$ http://gcep.stanford.edu/pdfs/ DyUMPHW1jsSmjoZfm2XEqg/1.4-Ziagos.pdf $>$. Date of access: May 9, 2008. 


\section{Appendix \\ Initial Values, Parameters and Calibration}

This section provides sources for the initial values and parameters which were not discussed in Section III, in particular $H_{1}, E N_{1}, \alpha_{K}, \alpha_{L}, A_{1}, \eta, \Phi_{t}, \alpha_{K}, \alpha_{H}, \rho$, and $a$. As well, we also provide additional commentary on the rate of time preference $\theta$.

Data do not exist for $H_{l}$. Even if data did exist, the value could be normalized arbitrarily, which would affect the values of the scale parameters $\alpha_{H}$ and $a$. Thus we can pick the value of $H_{1}$ arbitrarily and let the calibration take care of the scale parameters. We choose $H_{1}=0.01$.

We define an efficiency factor, $E F F$, for the world energy system, which measures the proportion of energy input converted into useful energy output in the initial period. We estimate $E F F=0.504$ from Ziagos and Berry (2006). We then use this value to estimate initial energy services, $E N_{l}$, as

$E N_{1}=E F F \cdot F_{1}$.

The remaining CES parameters $\alpha_{K}, \alpha_{L}$ and $A_{l}$ are determined by the equations

$$
\begin{aligned}
& \alpha_{K}=\frac{\alpha\left(E N_{1} / K_{1}\right)^{\gamma}}{1-\alpha\left[1-\left(\frac{E N_{1}}{K_{1}}\right)^{\gamma}\right]-\beta\left[1-\left(\frac{E N_{1}}{L_{1}}\right)^{\gamma}\right]} \\
& \alpha_{L}=\frac{\beta\left(E N_{1} / L_{1}\right)^{\gamma}}{1-\alpha\left[1-\left(\frac{E N_{1}}{K_{1}}\right)^{\gamma}\right]-\beta\left[1-\left(\frac{E N_{1}}{L_{1}}\right)^{\gamma}\right]} \\
& A_{1}=\frac{Q_{1}}{D_{1} E N_{1}}\left\{1-\alpha\left[1-\left(\frac{E N_{1}}{K_{1}}\right)^{\gamma}\right]-\beta\left[1-\left(\frac{E N_{1}}{L_{1}}\right)^{\gamma}\right]\right\}^{\frac{1}{\gamma}}
\end{aligned}
$$

These three equations are derived from market equilibrium conditions - i.e. $\partial Y / \partial K=r$ and $\partial Y / \partial L=w$ where $r$ represents the rental rate of capital and $w$ the wage rate - combined with the production function (1).

The value of the capital adjustment cost parameter, $\eta=15.46$, is chosen to replicate as closely as possible the adjustment cost profile of Goulder and Summers' (1989) two-parameter specification. In particular, if we let $\xi\left(I_{t}, K_{t}\right)$ represent adjustment costs, these authors assume

$\xi\left(I_{t}, K_{t}\right)=\left\{\begin{array}{cl}\frac{\hat{\eta}}{2}\left(I_{t} / K_{t}-\zeta\right)^{2} K_{t}, & \text { for } I_{t} / K_{t}>\zeta \\ 0, & \text { for } I_{t} / K_{t} \leq \zeta\end{array}\right.$ 
with parameter values $\hat{\eta}=19.6$ and $\zeta=0.076$ based on empirical estimates from Summers (1981). For ease of programming, we prefer the one-parameter specification of McKibbin and Wilcoxen (1999), $\xi\left(I_{t}, K_{t}\right)=\frac{\eta}{2} \frac{I_{t}^{2}}{K_{t}}$. We have chosen the value of $\eta$ to minimize the sum of squared deviations between the two specifications over the range $0 \leq I_{t} / K_{t} \leq 1$.

We combine our choice of the pure rate of time preference, $\theta=0.03$, with logarithmic utility (16), which is equivalent to a choice of unity for the elasticity of marginal utility. More generally, the isoelastic form of utility is

$U\left(C_{t} / L_{t}\right)=\frac{\left(C_{t} / L_{t}\right)^{1-\varrho}-1}{1-\varrho}$ with $\varrho$ representing the elasticity of marginal utility. Nordhaus (2008) combines a pure rate of time preference of 1.5 percent $(\theta=0.015)$ with an elasticity value of $\varrho=2$. This combination of $\theta$ and $\varrho$ yields similar near-term results as ours. In contrast, Popp (2004) and Nordhaus and Boyer (2000) assume a declining rate of time preference, starting at 3 percent and declining exponentially thereafter, combined with logarithmic utility $\varrho=1$. This approach follows the trend of recent years that favours a declining social rate of discount for benefits and costs in the distant future (see Laibson 1997, Weitzman 2001, and Newell and Pizer 2003). While this approach may have merit in a normative context, we do not believe it is appropriate in a positive context, such as modeling business-as-usual. By definition, discount rates in a positive context are required to replicate agents' revealed preferences, which usually relate to sequences of choices over relatively short horizons. For this purpose, we find a constant rate of pure time preference more persuasive. Moreover, we would like to keep the planner's preferences (normative) and the representative agent's preferences (positive) identical, in order to avoid complications arising from distributional concerns in the second best. Therefore we opt for a constant rate of time preference.

We derive the time trend of exogenous energy-related technical change, $1 / \Phi_{\mathrm{t}}$, as well as the energy parameters $\alpha_{F}, \alpha_{H}, \rho$, and the research scaling parameter $a$ through calibration. ${ }^{21}$ Following Popp (2004), we calibrate $1 / \Phi_{\mathrm{t}}$ to reproduce the emissions path of DICE 99 (Nordhaus and Boyer 2000), under the assumptions of BAU and no R\&D. By assumption $\Phi_{1}=1$. When induced innovation is added to the model, the trend of exogenous technical change must be scaled back by an appropriate amount, since it now represents only non-R\&D

${ }^{21}$ All simulations are run using the GAMS software (www.gams.com). 
related changes (e.g. changes from learning-by-doing). In his central case, Popp reduces the trend of $1 / \Phi_{t}$ by 20 percent. We follow the same approach.

To calibrate $\alpha_{F}$ and $\alpha_{H}$, we begin by substituting condition (25) into condition (37) and dividing through by $P_{t}^{Y}$, yielding in the initial period

$$
\left(1-\alpha_{K}-\alpha_{L}\right) D_{1} Q_{1}^{1-\gamma} A_{1}^{\gamma} E N_{1}^{\gamma-\rho} \alpha_{F} F_{1}^{\rho-1} \Phi_{1}^{-\rho}=-\Delta \cdot \frac{P_{1}^{C m}}{P_{1}^{Y}}+P_{1}
$$

in the case of CES production and

$$
(1-\alpha-\beta) D_{1} Q_{1} E N_{1}^{-\rho} \alpha_{F} F_{1}^{\rho-1} \Phi_{1}^{-\rho}=-\Delta \cdot \frac{P_{1}^{C m}}{P_{1}^{Y}}+P_{1}
$$

in the case of Cobb-Douglas production. (We have dropped the carbon tax $\tau_{1}$ from the right-hand side since it is equal to zero in BAU.) The resource shadow price, $P_{1}^{C m}$, is non-zero in our model (i.e. the agent takes account of the scarcity rent). However, we do not expect it to be large relative to $P_{1}$ in the initial period, due to discounting and the highly convex nature of $(8){ }^{22}$ Therefore, for the purpose of calibration, we assume $P_{1}^{C m}=0$. With these adjustments, (A.2) reduces to the competitive outcome that the marginal product of $F$ (left-hand side) equals its price. Solving for $\alpha_{F}$, and taking advantage of (A.1) and $\Phi_{1}=1$, yields

$\alpha_{F}= \begin{cases}\frac{P_{1} F_{1}^{1-\gamma} E F F^{\rho-\gamma}}{\left(1-\alpha_{K}-\alpha_{L}\right) D_{1} Q_{1}^{1-\gamma} A_{1}^{\gamma}}, & C E S \\ \frac{P_{1} F_{1} E F F^{\rho}}{(1-\alpha-\beta) D_{1} Q_{1}}, & \text { Cobb-Douglas }\end{cases}$

It is then a simple matter to rearrange (3) and obtain

$$
\alpha_{H}=\frac{E N_{1}^{\rho}-\alpha_{F} F_{1}^{\rho}}{H_{1}^{\rho}} \text {. }
$$

(Note that $\hat{\mathrm{F}}_{1}=\mathrm{F}_{1}$, since $\Phi_{1}=1$.)

Our calibration of $a$ and $\rho$ is based upon two empirical regularities. First, the elasticity of energy R\&D with respect to fossil fuel price must equal 0.35, based on research in Popp (2002). Second, the initial value of energy related R\&D is $\$ 25$ billion (see our discussion of $R_{1}$ above). Starting with arbitrary initial values, we iterate on $a$ and $\rho$ until the desired regularities are

\footnotetext{
${ }^{22}$ The extraction cost $P_{t}$ is essentially constant for many years before increasing toward the end of the planning horizon.
} 
achieved. With each iteration, we update $\alpha_{F}$ (A.3) and $\alpha_{H}$ (A.4) as they are both dependent upon $\rho$.

We define the R\&D elasticity with respect to fossil fuel price in terms of differences across policy scenarios for the first period. Equation (26) indicates that the full price of fossil fuels (right-hand side of (26)) includes terms relating to pollution damage $\left(P_{t}^{M} / P_{t}^{Y}\right)$ and scarcity $\left(P_{t}^{C m} / P_{t}^{Y}\right)$, as well as the production cost $\left(P_{t}\right)$. Letting $\pi_{t}$ represent the full price of fossil fuels and $\varepsilon$ represent the elasticity, we have $\varepsilon=\frac{R_{1}^{*}-\hat{R}_{1}}{\frac{1}{2}\left(R_{1}^{*}+\hat{R}_{1}\right)} / \frac{\pi_{1}^{*}-\hat{\pi}_{1}}{\frac{1}{2}\left(\pi_{1}^{*}+\hat{\pi}_{1}\right)}$,

where the asterisk and hat notation indicate different scenarios. The differences across policy scenarios give us the necessary variation in $R$ and $\pi$ while the restriction to the first period ensures the constancy of otherwise confounding influences such as $Y$ and $H$ (ceteris paribus assumption) ${ }^{23}$ For the two scenarios in (A.5), we choose two variants of BAU - the first as defined above and the second with the fuel price intercept $\omega_{1}$ increased by one percent.

\footnotetext{
${ }^{23}$ Popp (2003, 2006) defines an inter-temporal version of (A.5) and argues that it should decline over time to reflect diminishing returns to R\&D. We find this approach problematic since it does not hold constant $Y$ and $H$ and therefore it violates the ceteris paribus requirement of the elasticity. Furthermore, we believe that the claim of diminishing returns to energy R\&D is based on confusion in an earlier paper, Popp (2002), between depreciation of knowledge capital and diminishing returns. As explained above, a positive value of $\phi$ in the research equation (5) corresponds with the "standing on the shoulders" hypothesis, under which the marginal product of research $\partial h_{t} / \partial R_{t}$ increases as the knowledge stock $H_{t}$ increases. At the same time, the payoff to research is reduced if the knowledge stock depreciates over time due to obsolescence. It is this latter effect which Popp (2002) refers to as diminishing returns. In contrast, there is no depreciation of the knowledge stock in our model nor in ENTICE.
} 
Table 1

Value of $\boldsymbol{\psi}$

\begin{tabular}{|c|ccccccccc|}
\hline & \multicolumn{10}{|c|}{ duplication, $b$} \\
\cline { 2 - 10 } leakage, $\ell$ & 0.2 & 0.3 & 0.4 & 0.5 & 0.6 & 0.7 & 0.8 & 0.9 & 1.0 \\
\hline 0.00 & 0.20 & 0.30 & 0.40 & 0.50 & 0.60 & 0.70 & 0.80 & 0.90 & 1.00 \\
0.10 & 0.22 & 0.33 & 0.44 & 0.56 & 0.67 & 0.78 & 0.89 & 1.00 & 1.11 \\
0.20 & 0.25 & 0.38 & 0.50 & 0.63 & 0.75 & 0.88 & 1.00 & 1.13 & 1.25 \\
0.30 & 0.29 & 0.43 & 0.57 & 0.71 & 0.86 & 1.00 & 1.14 & 1.29 & 1.43 \\
0.40 & 0.33 & 0.50 & 0.67 & 0.83 & 1.00 & 1.17 & 1.33 & 1.50 & 1.67 \\
0.50 & 0.40 & 0.60 & 0.80 & 1.00 & 1.20 & 1.40 & 1.60 & 1.80 & 2.00 \\
0.60 & 0.50 & 0.75 & 1.00 & 1.25 & 1.50 & 1.75 & 2.00 & 2.25 & 2.50 \\
0.70 & 0.67 & 1.00 & 1.33 & 1.67 & 2.00 & 2.33 & 2.67 & 3.00 & 3.33 \\
0.75 & 0.80 & 1.20 & 1.60 & 2.00 & 2.40 & 2.80 & 3.20 & 3.60 & 4.00 \\
0.80 & 1.00 & 1.50 & 2.00 & 2.50 & 3.00 & 3.50 & 4.00 & 4.50 & 5.00 \\
0.90 & 2.00 & 3.00 & 4.00 & 5.00 & 6.00 & 7.00 & 8.00 & 9.00 & 10.00 \\
\hline
\end{tabular}

Based on condition (21) under the assumption $\hat{P}^{H}=P^{H}$. 
Table 2

Initial Values and Parameters

\begin{tabular}{|c|c|c|c|c|c|}
\hline \multicolumn{4}{|c|}{ external sources } & \multicolumn{2}{|c|}{ calibrated values } \\
\hline$Y_{1}$ & 61.1 \$US trillion (2005) & $\phi$ & $0.5,0,-0.5$ & $A_{1}$ (CES) & 0.12514 \\
\hline$K_{1}$ & 137 \$US trillion (2005) & $\xi$ & 0.0028388 & $A_{1}(\mathrm{C}-\mathrm{D})$ & 0.15936 \\
\hline$L_{1}$ & 6514 million & $\omega_{1}$ & 0.27629 & $\alpha_{\mathrm{K}}$ & 0.03931 \\
\hline$F_{1}$ & 8.20 b.t.c. & $\omega_{2}$ & 0.7 & $\alpha_{\mathrm{L}}$ & 0.87345 \\
\hline$E N_{1}$ & 4.13 b.t.c. & $\Omega$ & 6000 b.t.c. & $\rho$ & $-0.437 *$ \\
\hline$H_{1}$ & 0.01 & $b_{11}$ & 0.810712 & $a$ & $0.01936 *$ \\
\hline$R_{1}$ & 0.025 \$US trillion (2005) & $b_{12}$ & 0.189288 & $\alpha_{\mathrm{F}}$ & $0.4034 *$ \\
\hline$P_{1}$ & $0.27629 \$$ thous/tonne $\mathrm{C}$ & $b_{21}$ & 0.097213 & $\alpha_{\mathrm{H}}$ & $0.0507 *$ \\
\hline$T E_{1}$ & $0.7307{ }^{\circ} \mathrm{C}$ & $b_{22}$ & 0.852787 & & \\
\hline$T L_{1}$ & $0.0068{ }^{\circ} \mathrm{C}$ & $b_{23}$ & 0.05 & & \\
\hline$C m_{1}$ & 0 b.t.c. & $b_{32}$ & 0.003119 & & \\
\hline$M A T_{1}$ & 808.9 b.t.c. & $b_{33}$ & 0.996881 & & \\
\hline$M U_{1}$ & 1255 b.t.c. & $C_{1}$ & 0.220 & & \\
\hline$M L_{1}$ & 18365 b.t.c. & $C_{2}$ & 3.0 & & \\
\hline$\alpha$ & 0.28 & $C_{3}$ & 0.300 & & \\
\hline$\beta$ & 0.6 & $C_{4}$ & 0.050 & & \\
\hline$\gamma$ & -1.5 & $\ell$ & 0.75 & & \\
\hline$\delta_{\mathrm{K}}$ & 0.10 & crowdout & 0.5 & & \\
\hline$\eta$ & 15.46 & $\theta$ & 0.03 & & \\
\hline$b$ & $0.2,0.7$ & & & & \\
\hline
\end{tabular}

b.t.c. - billion tonnes carbon

* calibrated values for Experiment 1, $\phi=0.5, b=0.7$ (for demonstration) 
Table 3

Assumptions in Experiments

\begin{tabular}{|c|c|c|c|c|}
\hline \multirow{2}{*}{ Experiment } & \multicolumn{4}{|c|}{ Assumptions } \\
\hline & optimal policy & production & opportunity cost & $\left(R_{1} \$\right.$ bill $)$ \\
\hline 1 & 1st best (carbon tax $+R \& D$ subsidy) & $\operatorname{CES}(\sigma=0.4)$ & $\hat{P}^{H}=P^{H}$ & 25.0 \\
\hline 2 & 1st best (carbon tax $+R \& D$ subsidy) & $C-D(\sigma=1)$ & $\hat{P}^{H}=P^{H}$ & 25.0 \\
\hline 3 & 1st best (carbon tax $+R \& D$ subsidy) & $\operatorname{CES}(\sigma=0.4)$ & $\hat{P}^{H}=\frac{1}{2} P^{H}$ & 25.0 \\
\hline 4 & 1st best (carbon tax $+R \& D$ subsidy) & $\operatorname{CES}(\sigma=0.4)$ & $\hat{P}^{H}=P^{H}$ & 384.9 \\
\hline 5 & 2nd best (carbon tax alone) & $\operatorname{CES}(\sigma=0.4)$ & $\hat{P}^{H}=P^{H}$ & 25.0 \\
\hline 6 & 2nd best (carbon tax alone) & $\operatorname{CES}(\sigma=0.4)$ & $\hat{P}^{H}=\frac{1}{2} P^{H}$ & 25.0 \\
\hline
\end{tabular}

Table 4

R\&D Subsidy (\%)

(2005-2100 average)

\begin{tabular}{|c|c|c|c|c|c|}
\hline$\phi=0.5, b=0.7$ & $\phi=0.0, b=0.7$ & $\phi=-0.5, b=0.7$ & $\phi=0.5, b=0.2$ & $\phi=0.0, b=0.2$ & $\phi=-0.5, b=0.2$ \\
\hline 0.35 & 0.32 & 0.30 & -0.12 & -0.13 & -0.13 \\
\hline
\end{tabular}

Table 5

\section{Carbon Tax 2000-2010}

(\$US / tonne C)

\begin{tabular}{|c|c|c|c|}
\hline \multicolumn{2}{|c|}{$\phi=0.5, b=0.7$} & \multicolumn{2}{c|}{$\phi=0.5, b=0.2$} \\
\hline FB & SB & FB & SB \\
\hline 31.60 & 28.56 & 32.14 & 28.90 \\
\hline
\end{tabular}

$\mathrm{FB}=$ first best (Experiment 1)

$\mathrm{SB}=$ second best (Experiment 5) 
Table 6

Increase in Welfare Gain $\left(\Delta^{2} W\right)$ due to Induced R\&D (\%)

\begin{tabular}{|c|c|c|}
\hline Experiment 1 & $b=0.2$ & $b=0.7$ \\
\hline$\phi=0.5$ & 0.07 & 120.68 \\
\hline$\phi=0.0$ & 0.09 & 96.28 \\
\hline$\phi=-0.5$ & 0.11 & 79.18 \\
\hline AVG & 0.09 & 98.72 \\
\hline
\end{tabular}

\begin{tabular}{|c|c|c|}
\hline Experiment 2 & $b=0.2$ & $b=0.7$ \\
\hline$\phi=0.5$ & 0.05 & 59.70 \\
\hline$\phi=0.0$ & 0.06 & 37.78 \\
\hline$\phi=-0.5$ & 0.07 & 28.15 \\
\hline AVG & 0.06 & 41.88 \\
\hline
\end{tabular}

\begin{tabular}{|c|c|c|}
\hline Experiment 3 & $b=0.2$ & $b=0.7$ \\
\hline$\phi=0.5$ & 1.51 & 507.40 \\
\hline$\phi=0.0$ & 1.41 & 429.75 \\
\hline$\phi=-0.5$ & 1.31 & 373.17 \\
\hline AVG & 1.41 & 436.77 \\
\hline
\end{tabular}

\begin{tabular}{|c|c|c|}
\hline Experiment 4 & $b=0.2$ & $b=0.7$ \\
\hline$\phi=0.5$ & 1.11 & 519.75 \\
\hline$\phi=0.0$ & 0.93 & 279.76 \\
\hline$\phi=-0.5$ & 4.17 & 174.53 \\
\hline AVG & 2.07 & 324.68 \\
\hline
\end{tabular}

\begin{tabular}{|c|c|c|}
\hline Experiment 5 & $b=0.2$ & $b=0.7$ \\
\hline$\phi=0.5$ & -0.39 & 14.29 \\
\hline$\phi=0.0$ & -0.42 & 12.38 \\
\hline$\phi=-0.5$ & -0.44 & 10.87 \\
\hline AVG & -0.42 & 12.51 \\
\hline
\end{tabular}

\begin{tabular}{|c|c|c|}
\hline Experiment 6 & $b=0.2$ & $b=0.7$ \\
\hline$\phi=0.5$ & 0.82 & 24.70 \\
\hline$\phi=0.0$ & 0.78 & 22.20 \\
\hline$\phi=-0.5$ & 0.74 & 20.13 \\
\hline AVG & 0.78 & 22.34 \\
\hline
\end{tabular}


Figure 1

World GDP \& Consumption per capita

(Business-as-usual, $\phi=0.5, b=0.7$ )

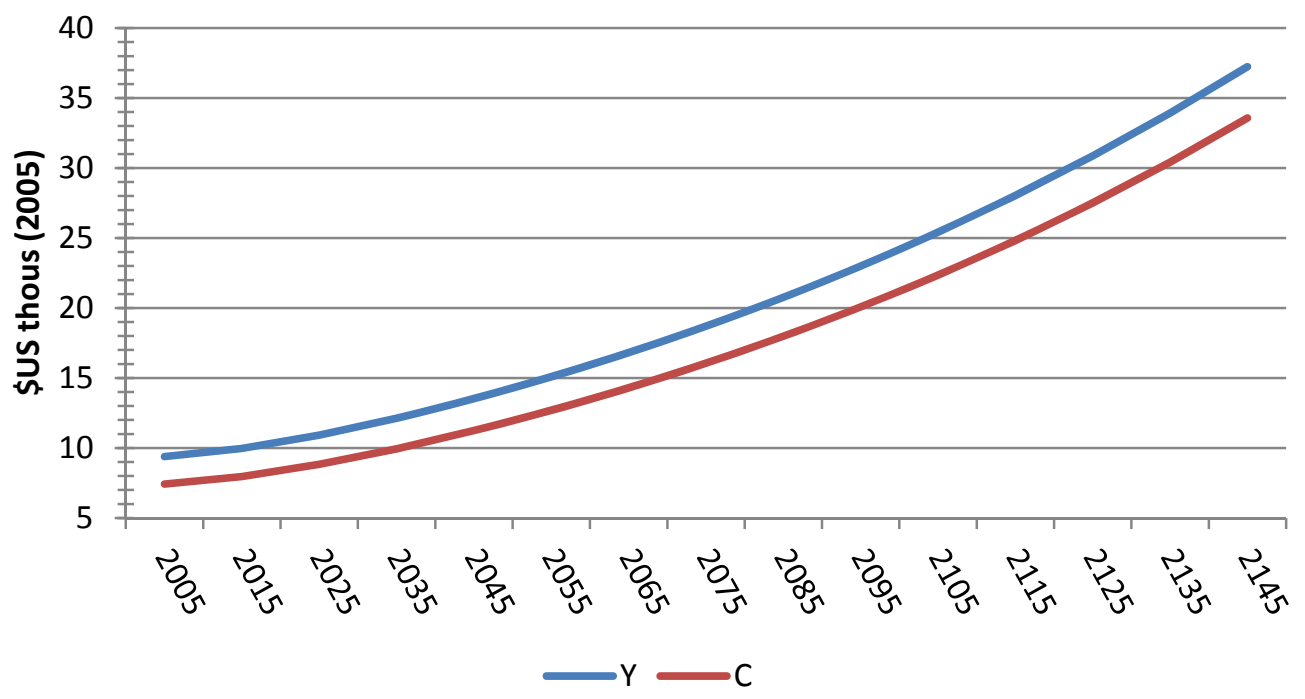

Figure 2

World GDP

(first-best relative to $\mathrm{BAU}$ )

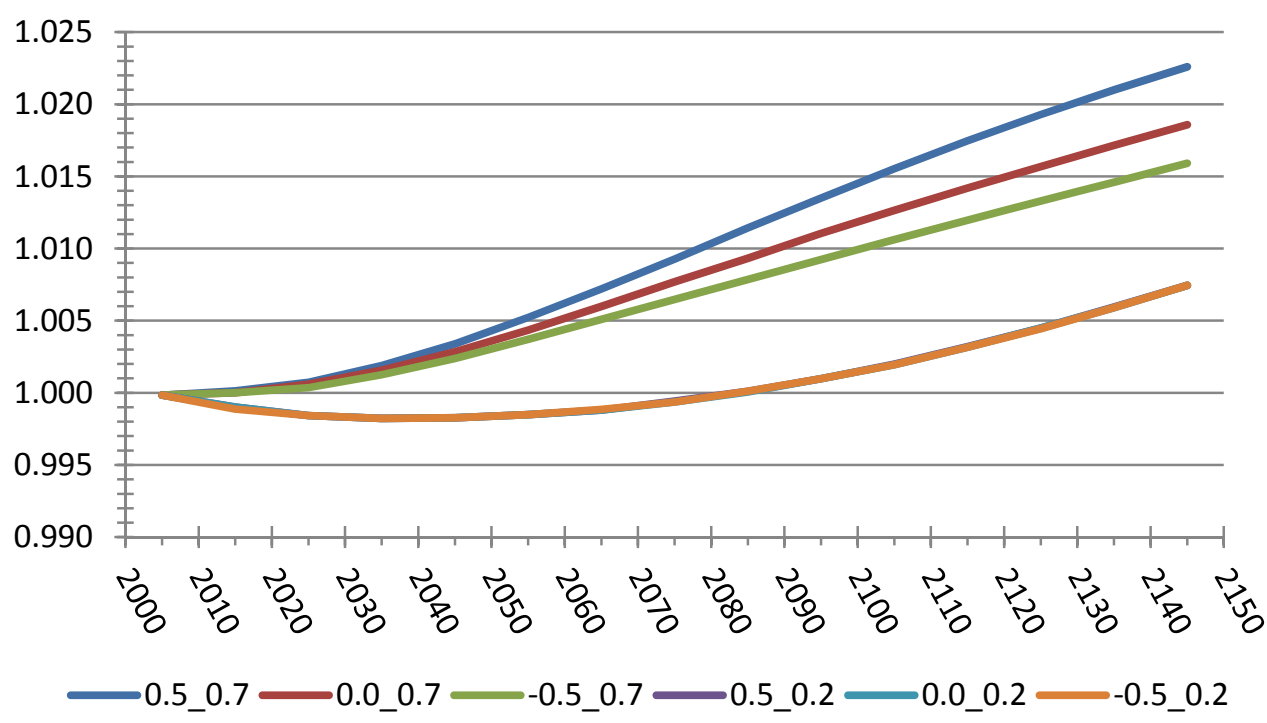

xx _yd denotes $\phi$ and $b$ values respectively

49 


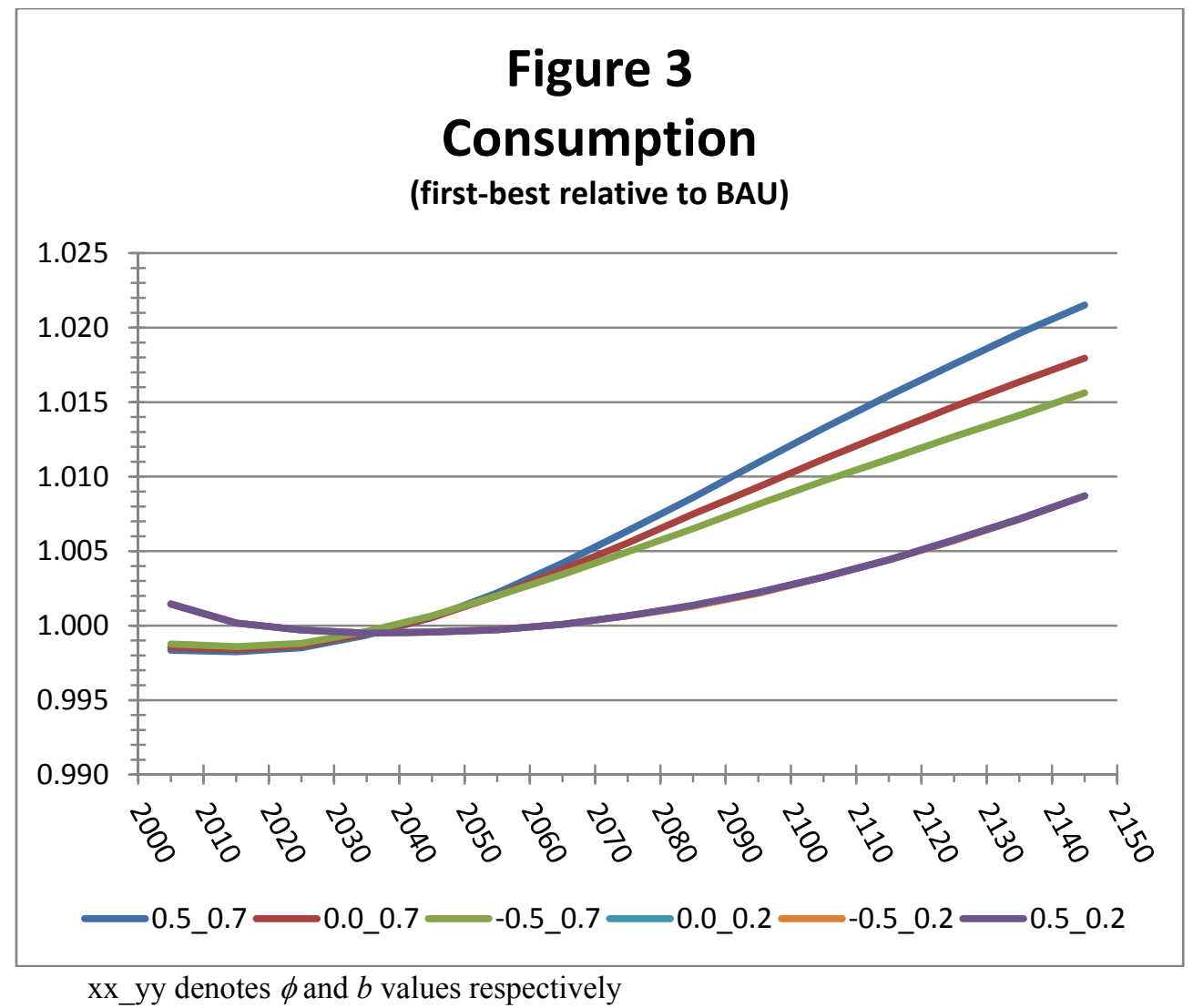

Figure 4

World R\&D Expenditure

$$
(\phi=0.5, b=0.7)
$$

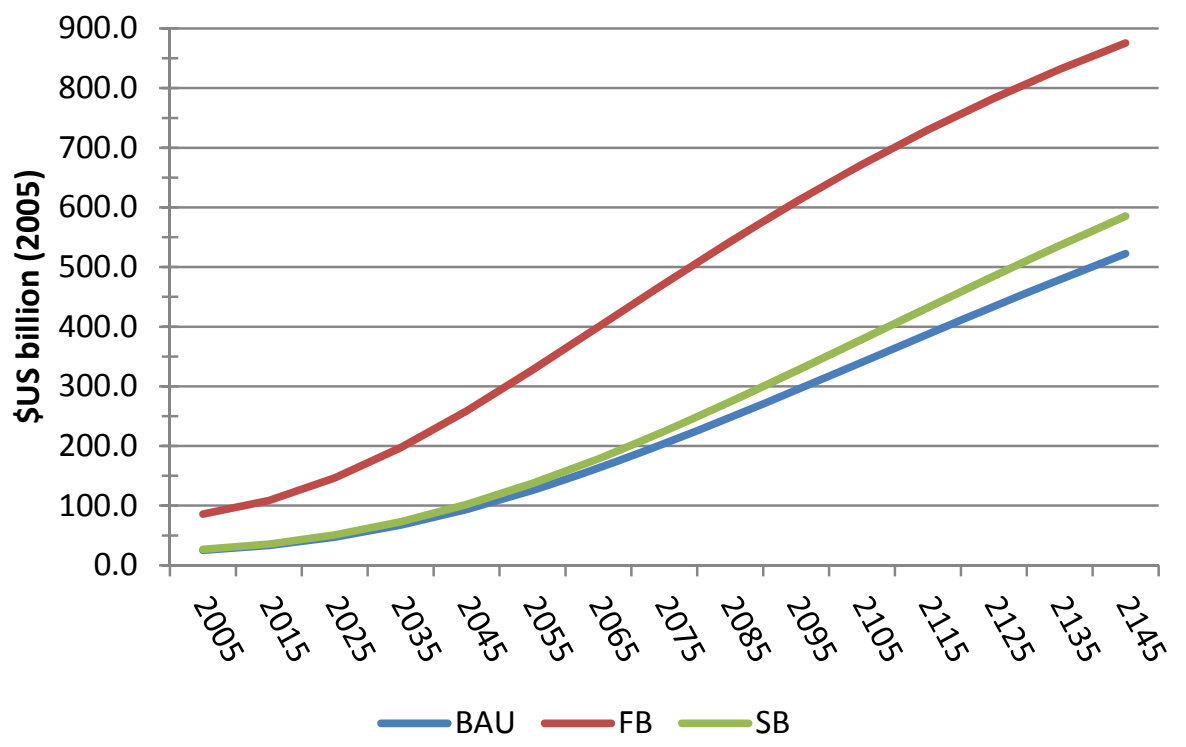

50 


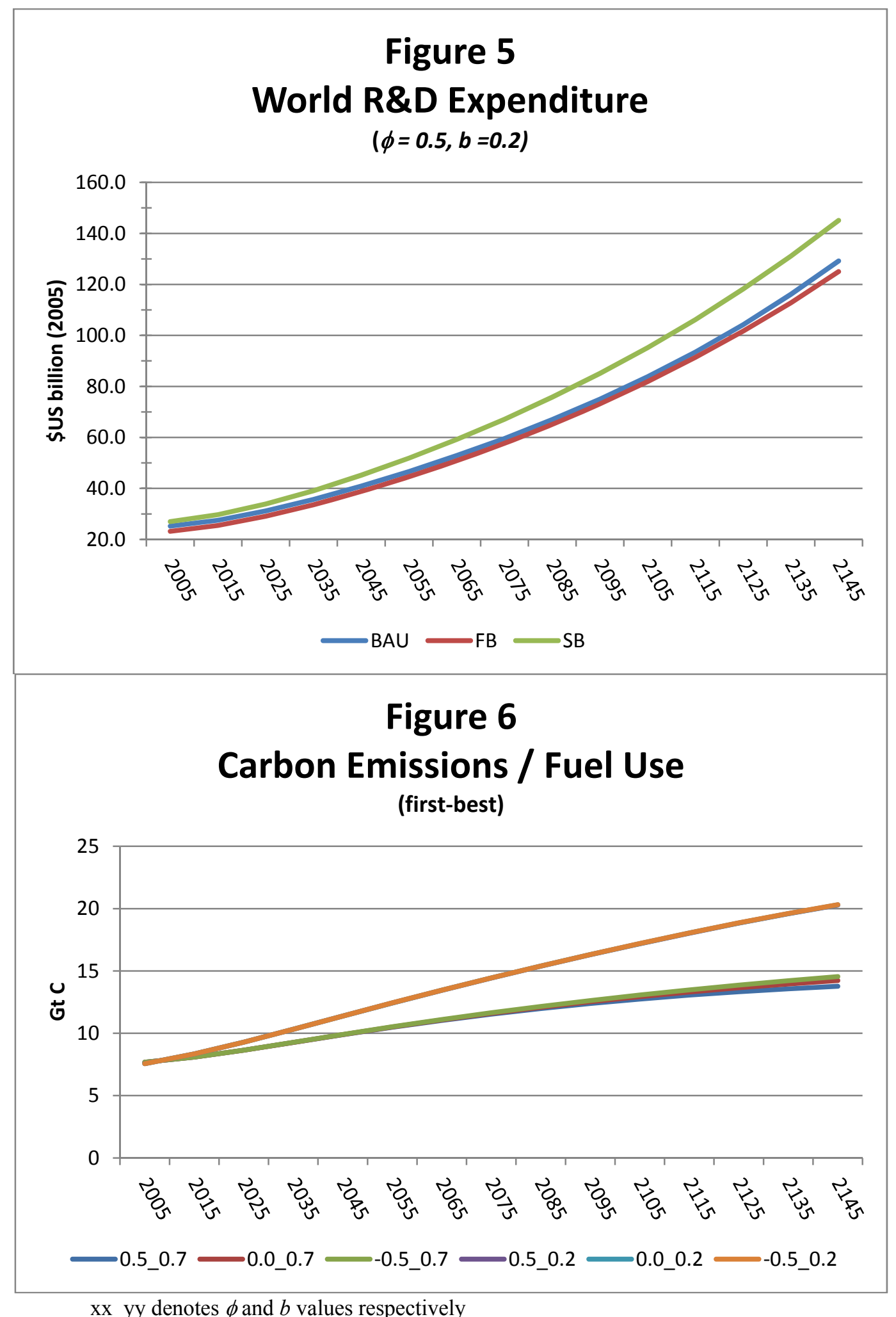

51 


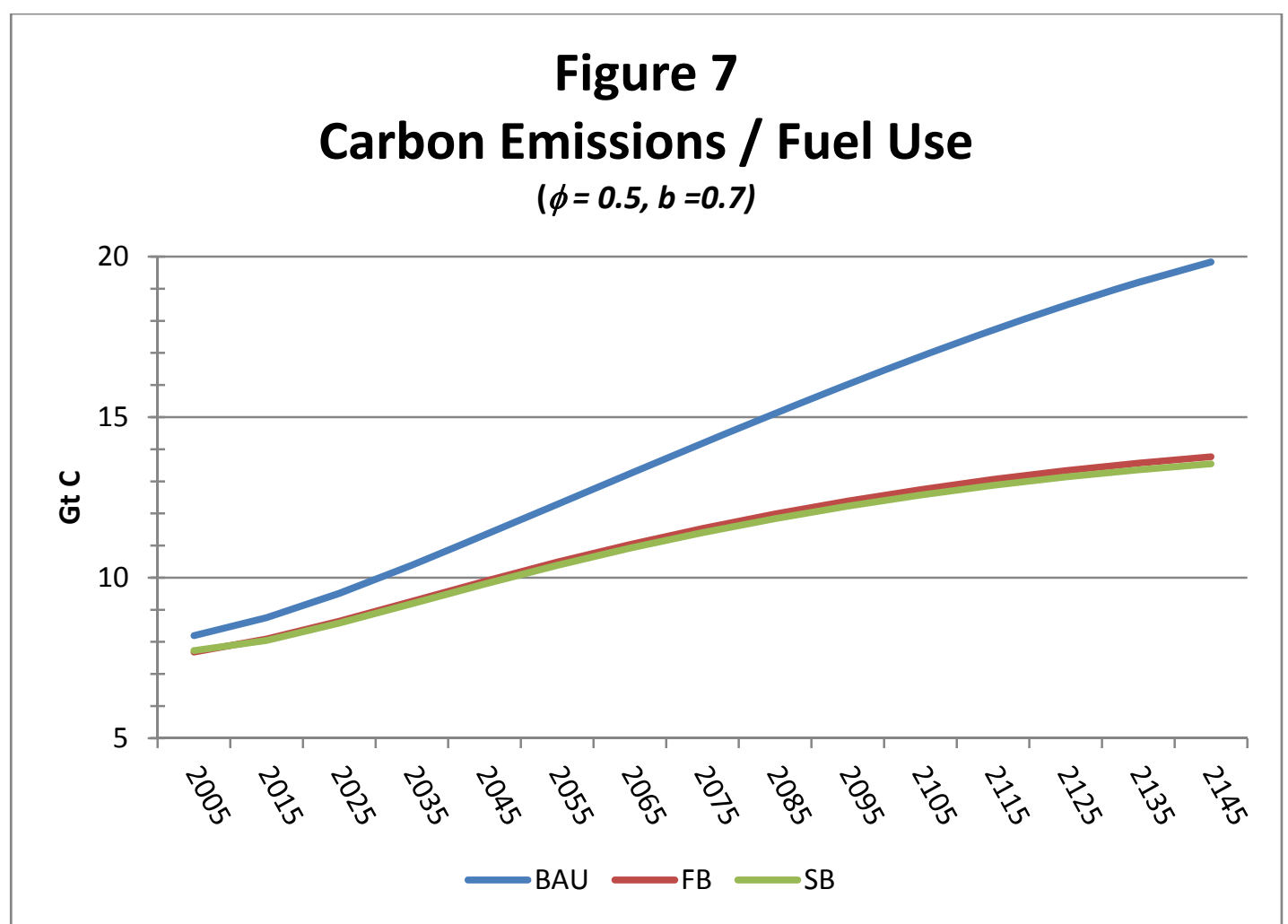

Figure 8

World Average Temperature $(\phi=0.5, b=0.7)$

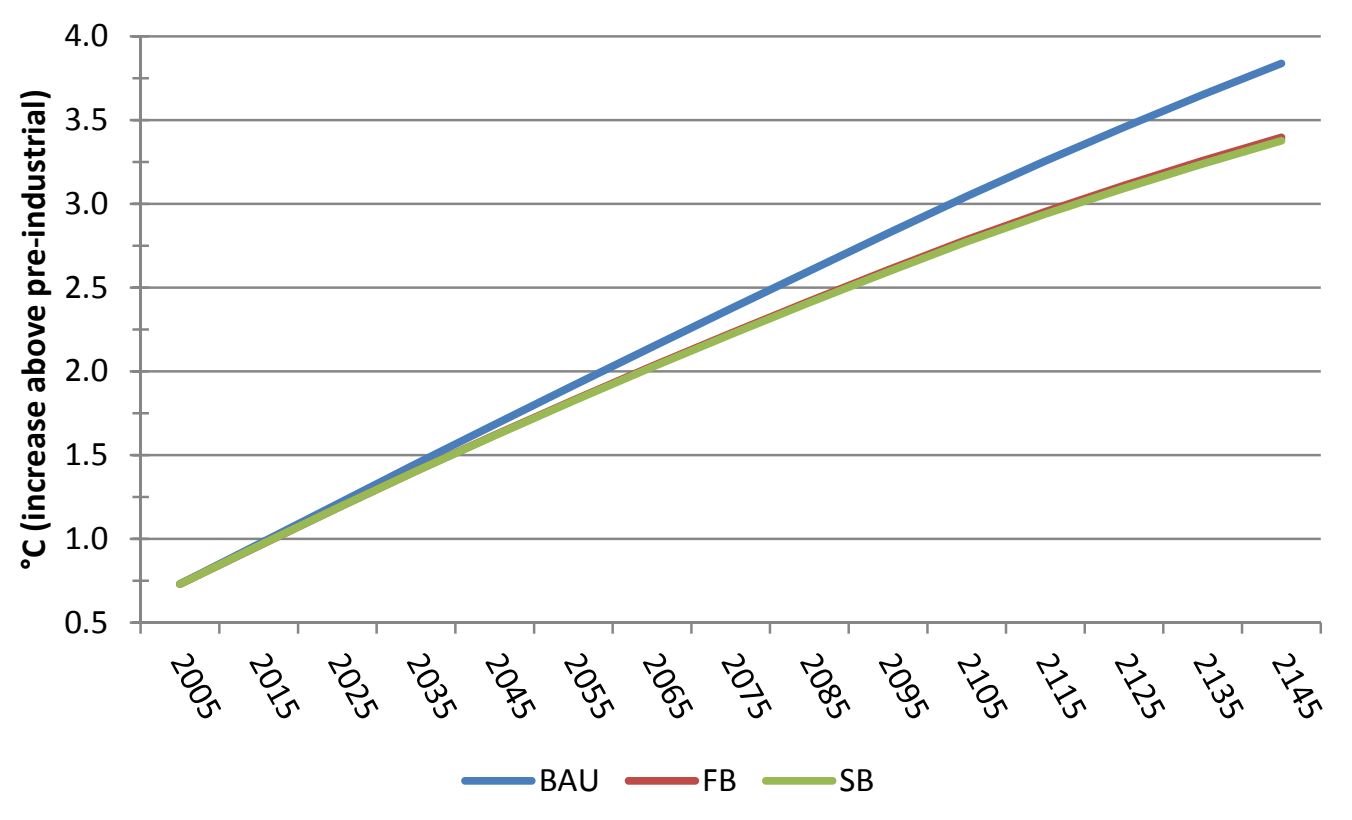

52 
Figure 9

Carbon Tax

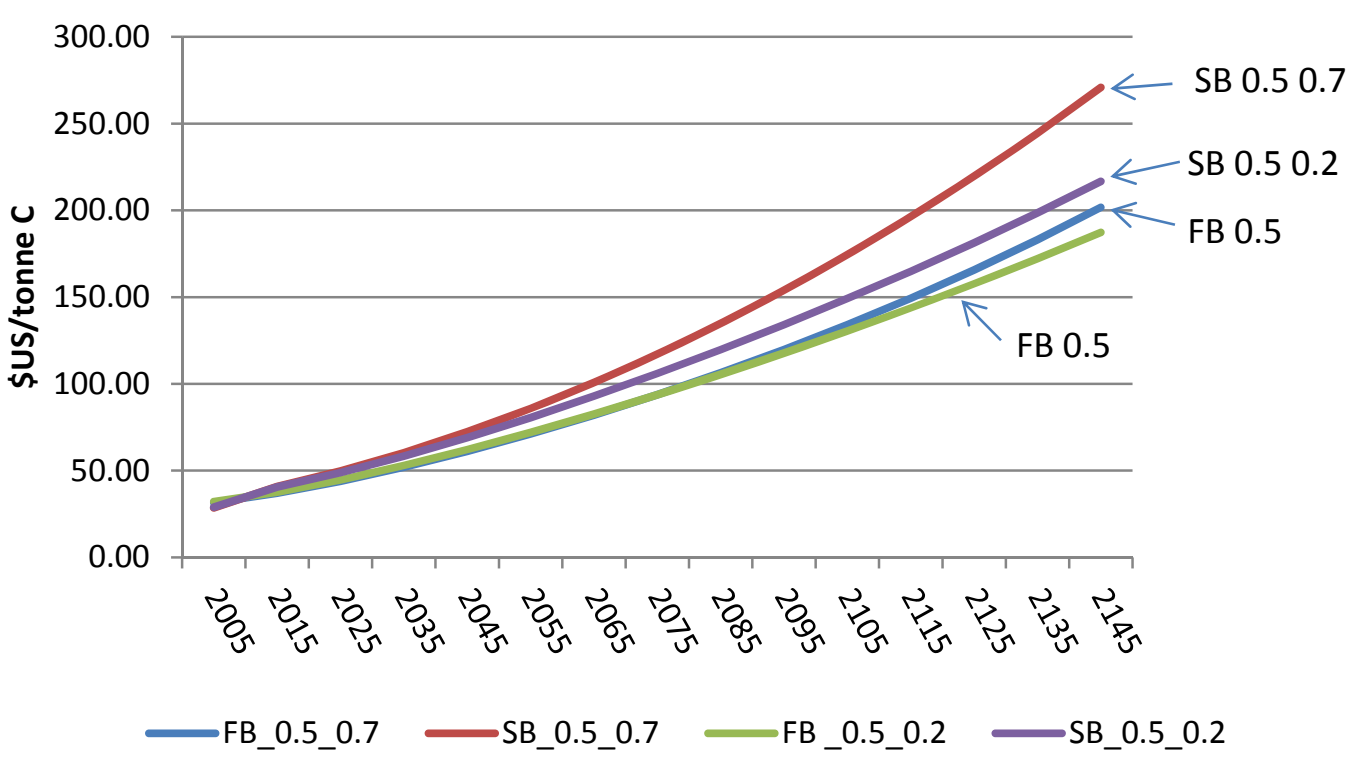

xx _yd denotes $\phi$ and $b$ values-- respectively

53 